\title{
Ionic Liquids in Catalysis
}

\author{
Hans-Peter Steinrück • Peter Wasserscheid
}

Received: 30 October 2014/Accepted: 12 November 2014/Published online: 27 November 2014

(C) Springer Science+Business Media New York 2014

\begin{abstract}
Ionic liquids (ILs), salts with melting points below $100{ }^{\circ} \mathrm{C}$, represent a fascinating class of liquid materials typically characterized by an extremely low vapor pressure. Besides their application as new solvents or as electrolytes for electrochemical purposes, there are two important concepts of using ILs in catalysis: Liquid-liquid biphasic catalysis and IL thin film catalysis. Liquid-liquid biphasic catalysis enables either a very efficient manner to apply catalytic ILs, e.g. in Friedel-Crafts reactions, or to apply ionic transition metal catalyst solutions. In both cases, phase separation after reaction allows an easy separation of reaction products and catalyst re-use. One problem of liquidliquid biphasic catalysis is mass transfer limitation. If the chemical reaction is much faster than the liquid-liquid mass transfer the latter limits the overall reaction rate. This problem is overcome in IL thin film catalysis where diffusion pathways and thus the characteristic time of diffusion are short. Here, Supported Ionic Liquid Phase (SILP) and Solid Catalyst with Ionic Liquid Layer (SCILL) are the two most important concepts. In both, a high surface area solid substrate is covered with a thin IL film, which contains either a homogeneously dissolved transition metal complex for SILP, or which modifies catalytically active surface sites at the support for SCILL. In each concept, interface phenomena
\end{abstract}

\footnotetext{
H.-P. Steinrück ( $\bowtie)$

Lehrstuhl für Physikalische Chemie II, Friedrich-Alexander-

Universität Erlangen-Nürnberg, Egerlandstrasse 3,

91058 Erlangen, Germany

e-mail: hans-peter.steinrueck@fau.de

P. Wasserscheid

Lehrstuhl für Chemische Reaktionstechnik, Friedrich-

Alexander-Universität Erlangen-Nürnberg, Egerlandstrasse 3,

91058 Erlangen, Germany

e-mail: peter.wasserscheid@fau.de
}

play a very important role: These may concern the interface of an IL phase with an organic phase in the case of liquidliquid biphasic catalysis. For IL thin film catalysis, the interfaces of the IL with the gas phase and with catalytic nanoparticles and/or support materials are of critical importance. It has recently been demonstrated that these interfaces and also the bulk of ILs can be investigated in great detail using surface science studies, which greatly contributed to the fundamental understanding of the catalytic properties of ILs and supported IL materials. Exemplary results concerning the IL/vacuum or IL/gas interface, the solubility and surface enrichment of dissolved metal complexes, the IL/support interface and the in situ monitoring of chemical reactions in ILs are presented.

Keywords Heterogeneous catalysis - Catalysis . Homogeneous catalysis - Green chemistry - Evaporation . Methodology and Phenomena - XPS - Spectroscopy and General Characterisation - Ionic liquids · Preparation and Materials

\section{Introduction to Ionic Liquids}

Ionic liquids (ILs) are defined as salts with a melting point below $100{ }^{\circ} \mathrm{C}$ and are-particularly in case of aprotic ILs-liquids characterized by very low vapor pressures. They represent a class of liquid materials with unique property profiles originating from a complex interplay of Coulombic, hydrogen bonding, and van-der-Waals interactions of their ions [1]. Understanding and utilizing these complex interactions represents the heart of ionic liquid science [2], and has resulted in a wide range of IL-based innovative research concepts and industrial applications, as impressively documented by a number of recent reviews 


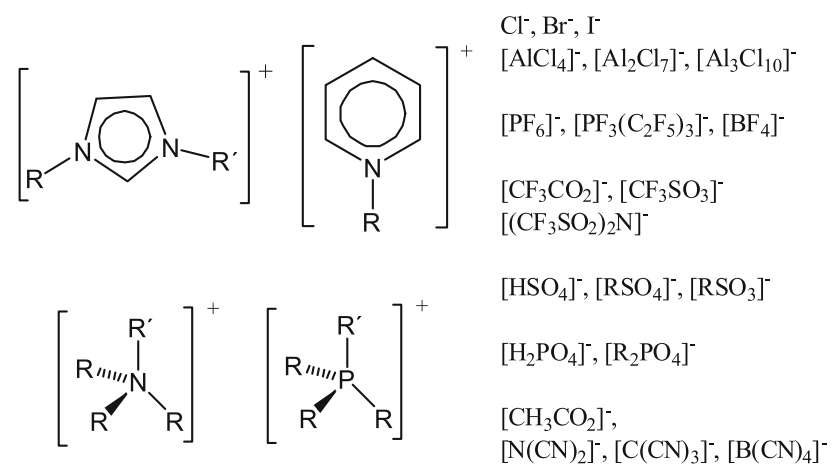

Fig. 1 Typical cations and anions forming ionic liquids

[3-6]. Figure 1 shows a list of typical cations and anions for the formation of ionic liquids.

The substituents R and R' can vary independently and may include linear alkyl chains as well as highly functionalized, branched, aromatic or cyclic moieties. The combination with the large number of anions that have proven to result in low melting salts yields an enormous structural variability of ionic liquids. Despite this great variability and the resulting diversity in some physicochemical properties, such as e.g. solubility, miscibility, melting point, viscosity, it is also important to state that their ionic nature also brings along some general limitations of ILs: for example, it will be difficult to design a highly volatile, non-conductive or absolutely unpolar IL. Table 1 shows an overview of typical ranges of physicochemical properties of interest. Much more detailed information about the specific properties of ILs can be found for example in Ref. [2].

The different characteristics allow for selecting the right IL for a given application. While ILs with "cheap" anions, such as e.g. toluenesulfonates [8], octylsulfates [9] and hydrogensulfates [10] are used, for example, in potential bulk applications (e.g. in synthesis, catalysis, separation technologies, lubrication, formulation, antistatics, materials technologies, biomass applications), ILs with "expensive" functionalized [11], fluorinated [12], deuterated [13] or even chiral ions [14] are interesting for small scale applications with very high added value (e.g. in analytical applications, sensors, electrolytes, coatings). Selecting the most suitable cation/anion combination for a given application has become much easier over the recent ten years, with a much greater set of experimental data being published [15-18] and some theoretical prediction tools being available now, such as the Conductor-like Screening Model for Real Solvent (COSMO-RS) approach [19, 20].

From the early times of ionic liquid science and technology on, catalysis has been identified as a very suitable and promising application area for ILs, since it makes specific use of some of their unique features, e.g. their unusual and highly tuneable solubility/miscibility

Table 1 Ranges of selected ionic liquid properties (from [2, 7] and references cited therein)

\begin{tabular}{|c|c|c|c|}
\hline Property & Lower limit example & $\begin{array}{l}\text { Typical range of } \\
\text { most ionic liquids }\end{array}$ & Upper limit example \\
\hline $\begin{array}{l}\text { Melting point/ } \\
\text { glass transition }\end{array}$ & $\begin{array}{l}{\left[\mathrm{C}_{2} \mathrm{C}_{1} \mathrm{Im}\right]^{\mathrm{a}} \mathrm{Cl} / \mathrm{AlCl}_{3}=1: 2:-96^{\circ} \mathrm{C}} \\
\quad \text { (glass transition) }\end{array}$ & $0-60{ }^{\circ} \mathrm{C}$ & $100{ }^{\circ} \mathrm{C}$ by definition \\
\hline Density & {$\left[\mathrm{C}_{6} \mathrm{C}_{1} \mathrm{Pyr}\right]^{\mathrm{b}}\left[\mathrm{N}(\mathrm{CN})_{2}\right]: 0.92 \mathrm{~g} / \mathrm{L}^{\mathrm{a}}$} & $1.1-1.6 \mathrm{~g} / \mathrm{L}^{\mathrm{c}}$ & {$\left[\mathrm{C}_{2} \mathrm{C}_{1} \mathrm{Im}\right] \mathrm{Br}: \mathrm{AlBr}_{3}=1 / 2: 2.2 \mathrm{~g} / \mathrm{L}^{\mathrm{a}}$} \\
\hline Viscosity & {$\left[\mathrm{C}_{2} \mathrm{C}_{1} \mathrm{Im}\right] \mathrm{Cl}: \mathrm{AlCl}_{3}=1 / 2: 14 \mathrm{mPa} \mathrm{s}$} & $40-800 \mathrm{mPa} \mathrm{s}$ & {$\left[\mathrm{C}_{4} \mathrm{C}_{1} \mathrm{Im}\right]^{\mathrm{d}} \mathrm{Cl}$ (super-cooled): $40.89 \mathrm{~Pa} \mathrm{~s}$} \\
\hline Thermal stability & {$\left[\mathrm{C}_{2} \mathrm{C}_{1} \operatorname{Im}\right][\mathrm{OAc}]:$ ca. $120{ }^{\circ} \mathrm{C}^{\mathrm{e}}$} & $230-300{ }^{\circ} \mathrm{C}^{\mathrm{e}}$ & {$\left[\mathrm{C}_{2} \mathrm{C}_{1} \operatorname{Im}\right]\left[\mathrm{Tf}_{2} \mathrm{~N}\right]^{\mathrm{f}}: 300{ }^{\circ} \mathrm{C}^{\mathrm{e}}$} \\
\hline Surface tension & {$\left[\mathrm{C}_{12} \mathrm{C}_{1} \mathrm{Im}\right]^{\mathrm{g}}\left[\mathrm{PF}_{6}\right]: 23.6 \mathrm{mN} / \mathrm{m}$} & $30-50 \mathrm{mN} / \mathrm{m}$ & {$\left[\mathrm{C}_{1} \mathrm{C}_{1} \mathrm{Im}\right]^{\mathrm{g}}\left[\mathrm{MeSO}_{4}\right]: 59.8 \mathrm{mN} / \mathrm{m}$} \\
\hline Heat capacity & {$\left[\mathrm{C}_{4} \mathrm{C}_{1} \mathrm{Im}\right]\left[\mathrm{MeSO}_{4}\right]: 247 \mathrm{~J} / \mathrm{mol} \mathrm{K}$} & $300-400 \mathrm{~J} / \mathrm{mol} \mathrm{K}$ & {$\left[\mathrm{C}_{8} \mathrm{C}_{1} \mathrm{Im}\right]^{\mathrm{g}}\left[\mathrm{Tf}_{2} \mathrm{~N}\right]: 654 \mathrm{~J} / \mathrm{mol} \mathrm{K}$} \\
\hline Water miscibility & {$\left[\mathrm{Tf}_{2} \mathrm{~N}\right]^{-},\left[\mathrm{P}\left(\mathrm{C}_{2} \mathrm{~F}_{5}\right)_{3} \mathrm{~F}_{3}\right]^{-}$} & $\begin{array}{l}\text { Many ILs do mix with water but can } \\
\text { be extracted from water }\end{array}$ & {$\left[\mathrm{RSO}_{3}\right]^{-},\left[\mathrm{RSO}_{4}\right]^{-},\left[\mathrm{R}_{2} \mathrm{PO}_{4}\right]^{-}$} \\
\hline Hydrolytic stability & {$\left[\mathrm{BF}_{4}\right]^{-},\left[\mathrm{PF}_{6}\right]^{-}$} & $\begin{array}{l}\text { Also heterocyclic cations can } \\
\text { hydrolyze under extreme conditions }\end{array}$ & {$\left[\mathrm{Tf}_{2} \mathrm{~N}\right]^{-},[\mathrm{TfO}]^{-},\left[\mathrm{CH}_{3} \mathrm{SO}_{3}\right]^{-}$} \\
\hline Prize $^{h}$ & {$\left[\mathrm{HNR}_{3}\right]\left[\mathrm{HSO}_{4}\right]:$ ca. $3 € / \mathrm{kg}$} & $25-250 € / \mathrm{kg}$ & {$\left[\mathrm{C}_{4} \mathrm{dmIm}\right]^{\mathrm{i}}\left[\mathrm{Tf}_{2} \mathrm{~N}\right]:$ ca. $1.000 € / \mathrm{kg}$} \\
\hline
\end{tabular}

${ }^{\mathrm{a}}\left[\mathrm{C}_{2} \mathrm{C}_{1} \mathrm{Im}\right]=$ 1-ethyl-3-methylimidazolium

${ }^{\mathrm{b}}\left[\mathrm{C}_{6} \mathrm{C}_{1} \mathrm{Pyr}\right]=1$-hexyl-1-methylpyrrolidinium

c At room-temperature

${ }^{\mathrm{d}}\left[\mathrm{C}_{4} \mathrm{C}_{1} \mathrm{Im}\right]=1$-butyl-3-methylimidazolium

${ }^{\mathrm{e}}$ Long-term stability

${ }^{\mathrm{f}}\left[\mathrm{Tf}_{2} \mathrm{~N}\right]=\left[\left(\mathrm{CF}_{3} \mathrm{SO}_{2}\right)_{2} \mathrm{~N}\right]$

g $\left[\mathrm{C}_{\mathrm{n}} \mathrm{C}_{1} \mathrm{Im}\right]=1$-alkyl-3-methylimidazolium

${ }^{\mathrm{h}}$ Estimation made for a production scale of $1.000 \mathrm{~kg}$ and for a purity $>98 \%$

${ }^{\mathrm{i}}\left[\mathrm{C}_{4} \mathrm{dmIm}\right]=1$-butyl-2,3 dimetylimidazolium $]$ 
properties or their unique combinations of polarity/nucleophilicity. Since these pioneering times, two important concepts of using ILs in catalysis have been developed: Liquid-ionic liquid biphasic catalysis and ionic liquid thin film catalysis.

Among the applications of ILs in liquid-ionic liquid biphasic catalysis, there are examples that use ILs which themselves represent the catalytically active part of the reaction system, such as e.g. in using acidic chloroaluminate melts in Friedel-Crafts reactions or refinery alkylation [21]. Alternatively, the IL may represent the bulk solvent for a transition metal catalyst forming a catalytically active ionic catalyst solution. In both cases, the miscibility gap between the ionic catalyst phase and the organic product phase allows for easy product isolation and catalyst recycling. However, one frequently encountered problem in liquid-ionic liquid biphasic catalysis is mass transfer limitation. This is due to the relatively high viscosity of the ionic catalyst phase [22] and the fast chemical reactions promoted by many ionic liquid catalyst systems. Slow mass transfer of substrates into the viscous melt thus often limits the overall reaction rate and reduces the ionic liquid utilization in the reaction, i.e. a great part of a given ionic liquid catalyst droplet is not in contact with the substrate due to the slow mass transfer [6].

One very promising approach to overcome these limitations is ionic liquid thin film catalysis. Providing the catalytically active phase in the form of a thin film shortens the diffusion pathways and thus the characteristic time of diffusion. Among ionic liquid thin film technologies two conceptually different cases can be distinguished:

- Supported Ionic Liquid Phase (SILP), which is characterized by the fact that the supported thin IL film contains a dissolved catalyst species thus representing the case of supported homogeneous catalysis;

- Solid Catalyst with Ionic Liquid Layer (SCILL), which is characterized by the fact that the solid support surface, or a catalyst deposited thereon, is catalytically active and the supported thin IL film does not contain any active catalyst, thus representing the case of an ILmodified heterogeneous catalysis.

Apart from these two borderline cases, there are also mixed and transition situations. It is well possible, for example, that under certain reaction conditions a SILP catalyst may undergo thermal degradation to a system containing supported, IL-stabilized catalyst nanoparticles. It is furthermore well possible under certain reaction conditions, that a SCILL catalyst transforms to a SILP-like system by dissolution of the active species from the solid surface into the IL film. In all these considerations it is important to be aware of the fact that under catalytic conditions the nature of the IL film is quite complex with dissolved substrate, products and side-products being present in addition to the catalyst.

In all named catalytic applications of ILs, interface phenomena play a very important role: These may concern the interface of an IL phase with an organic phase in the case of liquid-ionic liquid biphasic catalysis. For IL thin film catalysis, both the interface of the IL with solid support and with the second fluid phase (gas or liquid) is of high relevance.

The aim of this review is to set conceptual aspects of ionic liquid catalysis into context of recent advances in ionic liquid surface science. Such link has become recently possible by the great progress in studying IL interfaces by traditional UHV surface science techniques. In particular $\mathrm{X}$-ray photoelectron spectroscopy (XPS) has given access to the surface orientation, surface composition, segregation and reorganization phenomena at IL interfaces, giving new insights to liquid interfaces in general, at an unprecedented molecular level. Thus, our contribution aims to demonstrate how this new insights will allow for a more efficient development of ionic liquid catalyst systems for real world applications in the future.

\section{Liquid-Ionic Liquid Biphasic Catalysis}

As mentioned above, liquid-ionic liquid biphasic catalysis covers the two cases of (a) the IL being the active catalytic liquid, and (b) the IL being a solvent for a dissolved transition metal catalyst. A special case of (b) is that the IL phase contains stabilized catalytic nanoparticles in form of a stable suspension. These different cases will be highlighted in the following using characteristic and illustrative examples.

\subsection{Liquid-Ionic Liquid Biphasic Catalysis Using Acidic Chloroaluminates}

A number of key industrial processes in oil refining, petrochemistry and chemistry are acid-catalyzed. The traditional use of cheap and strong acids, such as $\mathrm{AlCl}_{3}$ or sulfuric acid, involves typical work-up protocols that lead to complete catalyst hydrolysis for product isolation. As a result, large quantities of corrosive waste water are formed which have to be treated in sophisticated down-stream processes due to their organic product residues. Moreover, all catalytic activity is lost during catalyst hydrolysis.

For these applications, acidic ILs offer unique advantages as they represent liquids of high acidity that can be tuned in their solubility, miscibility and acid strength [5, $21,23]$. The best investigated and most established representatives are chloroaluminate ILs that are formed by mixing a molar excess of $\mathrm{AlCl}_{3}$ with an organic chloride 
salt. Chloroaluminate melts are extremely hygroscopic in nature and more or less contaminated with water in almost all practically relevant applications [24]. Accordingly, acidic chloroaluminate ILs contain at least traces of oxy/ hydroxychloroaluminate species and molecular $\mathrm{HCl}$. It has been found already in the late 1980's that Brønsted superacidity results if gaseous $\mathrm{HCl}$ is added to acidic chloroaluminate melts and quantitative studies of the acidity of $\mathrm{HCl}$ in $\left[\mathrm{C}_{2} \mathrm{C}_{1} \mathrm{Im}\right] \mathrm{Cl} / \mathrm{AlCl}_{3}$ as a function of $\mathrm{HCl}$ pressure and IL composition (51.0-66.4 $\mathrm{mol} \% \mathrm{AlCl}_{3}$ ) have been published [25]. It is noteworthy that acidic chloroaluminates change their nature under vacuum conditions, since $\mathrm{HCl}$ and $\mathrm{AlCl}_{3}$ may evaporate/sublime from the $\mathrm{IL}$ thus changing composition and acidity of the melt.

Among the key applications of liquid-ionic liquid biphasic catalysis with acidic chloroaluminate ILs are Friedel-Crafts alkylation [26-29], Friedel-Crafts acylation [30-32] and carbonylation reactions [33-35]. Other important acid catalyzed reactions that have been successfully carried out in form of liquid-ionic liquid biphasic catalysis include oligomerization [36], cracking [37, 38] and refinery alkylation reactions [39-41]. The latter represent the transformation of short-chain olefins $\left(\mathrm{C}_{3}-\mathrm{C}_{5}\right)$ with isobutane to produce high octane fuels. This process is of particular importance as PetroChina has introduced a commercial alkylation process based on a composite catalyst system consisting of an acidic chloroaluminate IL and copper chloride. The addition of copper chloride led to higher selectivities to octanes and to a higher trimethylpentanes/dimethylhexanes ratio [42, 43]. In 2006, this process replaced an existing $65,000 \mathrm{t} \mathrm{a}^{-1}$ sulfuric acid alkylation plant in China [44] and is said to actually produce $100,000 \mathrm{t} \mathrm{a}^{-1}$ of alkylates using an ammonium saltbased catalyst system [45].

\subsection{Liquid-Ionic Liquid Biphasic Transition Metal Catalysis}

Apart from acidic catalysis, ILs have been intensively tested in the last two decades for the immobilization of homogenously dissolved transition metal catalysts. Successful catalyst immobilization techniques are essential for industrial homogeneous catalysis to solve the problem of catalyst/product separation and to recover and recycle the often very expensive, dissolved transition metal complexes. In multiphasic homogeneous transition metal catalysis, the polar catalyst phase must exhibit the following properties:

- sufficient solubility for the reactants and rapid mass transfer of the starting material into the catalyst phase;

- pronounced miscibility gap with the desired product and by-products;
- excellent solvation of the catalyst to ensure full catalyst immobilization and no leaching;

- no deactivation of the immobilized catalyst by the catalyst solvent.

Ionic liquids with their tunable solvation, polarity and nucleophilicity properties [46] are ideally suited to fulfill this complex set of requirements. Moreover, the liquidionic liquid biphasic reaction mode does not only allow to recycle the applied transition metal catalyst but also the comparatively expensive ionic liquid itself. Thus-for a commercial application-the IL may be seen in an ideal case as a one-time investment or at least as a "working solution" where only a small amount has to be replaced after a certain time of application.

A very important aspect in liquid-ionic liquid biphasic catalysis with transition metal catalysts is the applied ligand attached to the active metal in solution. To avoid catalyst leaching, the ligand has either to be highly polar or ionic. In order to deal with this issue much research has been devoted to synthesize ion-tagged versions of wellestablished ligand structures to maintain the well-known electronic and steric effect of a given ligand in a biphasic reaction system [47-49]. Figure 2 gives some examples for ionic or ion-tagged ligands (all with the $\left[\mathrm{PF}_{6}\right]^{-}$counter ion) that have been successfully used for hydrogenation, oxidation and hydroformylation reactions [50].

Transition metal catalysis in liquid-ionic liquid biphasic systems has been successfully performed in all areas that can be regarded as the classical domains of homogeneous catalysis, namely catalytic reactions at mild temperature conditions in which complex selectivity issues matter. Thus, over the last decade, hundreds of successful

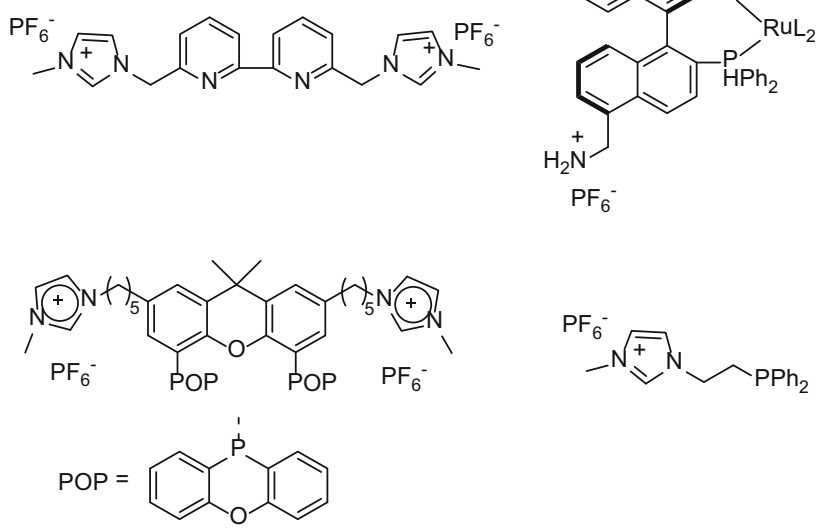

Fig. 2 Examples for ionic or ion-tagged ligands as successfully used to immobilize transition metal complexes in liquid-ionic liquid biphasic reaction systems 
examples of biphasic hydrogenation, oxidation, hydroformylation, dimerization, telomerization and oligomerization reactions have been published as well as numerous Pdcatalyzed coupling reactions. The reader interested in a complete picture of these huge research activities is referred to a large set of excellent reviews, for examples by Wu et al. [51], Geldbach [52], Parvulescu and Hardacre [53], Haumann and Riisager [54], Wasserscheid and Schulz [50], Olivier-Bourbigou et al. [55] as well as by Jutz et al. [56].

ILs are also very interesting media for preparing and stabilizing catalytic nanoparticles [57-59]. In most cases, the stabilization mechanism includes formation of protective layers of supramolecular structures through loosely bound anions or N-heterocyclic carbenes. However, the surface-bound protective species are easily displaced by other substances in the media. This hemilabile character of the protection layer explains both the catalytic activity and the relatively low stability of IL-stabilized nanoparticles against aggregation/agglomeration. More stable nanoparticle-based catalytic systems can be obtained in ILs by the addition of ligands or polymeric stabilizers. Transitionmetal nanoparticles dispersed in ILs have been described as active catalysts for various reactions such as the hydrogenation of alkenes, arenes and ketones [60]. Further examples are given in dedicated reviews by Gu [78] and Dupont [57]. In most reported cases, the reactions have been carried out as liquid-ionic liquid biphasic systems with the nanoparticles dispersed in the IL forming the catalyst phase while the starting material and the product form the upper organic phase. As in the case of homogeneous IL catalysis, the IL-nanoparticle phase is easily recovered by simple decantation.

\section{Supported Ionic Liquid Phase (SILP) Catalysis}

One significant problem in all attempts to transfer liquidionic liquid biphasic catalysis to industrial application is the use of bulk quantities of ionic liquids and the "technical risk" related to this. This risk stems from the fact that ILs are-regardless of their good commercial availability nowadays - typically by a factor of 10-50 more expensive than the organic solvents they often aim to substitute. This draws a lot of attention to the aspects of IL lifetime, IL stability and last but not least to the IL cost per kilogram (which usually is a strong function of the IL quality). Moreover, there are practical questions related to the handling of liquid salts in large quantities, such as the compatibility with plant materials, sealings in pumps or the disposing of spent IL. Corrosion, swelling, or embrittlement are other relevant effects in this context. In the last ten years, attempts to minimize the risk of applying ILs in practical applications led straightaway to IL thin film technologies. Using ILs as thin films greatly reduces all IL specific investment and many potential problems that scale with the quantity of IL. However, the successful application of IL thin film technologies requires a much better understanding of IL-surface and IL-interface phenomena, as these latter two dominate the IL behavior more and more as the IL film gets thinner and thinner.

SILP catalysis was developed to exploit these obvious advantages of IL thin film technologies for the field of catalysis. A SILP catalyst comprises a thin film of ionic catalyst solution immobilized on a highly porous support material. The outstanding advantage of SILP systems compared to a classical biphasic system is-besides the very thin film of IL - the high specific IL-fluid interfacial area. A SILP material provides the whole IL volume close to the fluid-fluid phase boundary, that is, within the diffusion layer. Thus, mass transfer influence can be excluded as long as there is no other liquid (e.g. product condensate) in the pores of the support. The absence of mass transfer limitation leads to an extremely efficient use of the ionic liquid catalyst volume and, therefore, to a higher catalytic productivity with respect to the applied amount of IL and catalytic metal. Besides, the SILP concept combines in a very attractive manner the advantages of classical homogeneous catalysis (high activity under mild condition and high, ligand-modified selectivity) and heterogeneous catalysis (simple product separation, catalyst recycling and continuous processing). Typically, the IL is held on the porous support by capillary forces, electrostatic interactions and hydrogen-bond interactions (e.g. between the IL ions and the surface $-\mathrm{OH}$ groups of the support). SILP catalysts are highly suitable for continuous gas-phase processes in fixed-bed reactors due to the very low volatility of typical ionic catalyst solutions. Operating in the slurry-phase reaction mode, in contrast, is only reasonable if the cross solubility of the supported IL with the reactant/ product/solvent phase is extremely low.

SILP catalysis was introduced by Mehnert in 2002 for slurry phase hydroformylation and hydrogenation reactions [61, 62]. Shortly later, Riisager et al. published the first successful example of continuous gas-phase SILP catalysis [63]. During the last years, many technically relevant examples of SILP catalysis have been published, including examples of hydroformylation $[64,65]$, hydrogenation [66, 67], enantioselective hydrogenation [68, 69], water gas shift reaction [70, 71], alkene metathesis [72, 73], hydroamination [74] and carbonylation of methanol [75]. Additional valuable information about SILP catalysis has been collected in reviews by Riisager et al. [76, 77], Gu and $\mathrm{Li}$ [78], van Doorslaer et al. [79], and Virtanen et al. [80]. The whole field has recently been summarized in an excellent book by Fehrmann et al. [81]. 
The IL film distribution in SILP catalysts was studied with solid-state NMR [82]. In these studies, no homogeneous IL film but island formation was proposed for IL loadings $<10$ vol\% (referred to the total pore volume of the porous support). Lemus characterized SILP materials that were prepared with different supports [83]. Pore size distributions with varying amounts of $\left[\mathrm{C}_{8} \mathrm{C}_{1} \mathrm{Im}\right]\left[\mathrm{PF}_{6}\right]$ on activated carbon were measured and analyzed with a combination of adsorption-desorption isotherms of $\mathrm{N}_{2}$ at $77 \mathrm{~K}$ and mercury porosimetry. Lemus suggested hierarchically pore filling, firstly the micropores, followed by the mesopores and finally the macropores. Lercher et al. reported on the complete coverage of the porous silica surface with IL analyzed with IR absorption spectroscopy [84]. Jess investigated $\left[\mathrm{C}_{4} \mathrm{C}_{1} \mathrm{Im}\right]$ octylsulfate loadings on porous solid catalyst $\mathrm{Ni} / \mathrm{SiO}_{2}$ [85]. $\mathrm{N}_{2}$-adsorption measurements indicated that the surface area decreases with increasing IL pore filling degree. The micro- and mesopores were partially or completely filled for a pore filling degree of $20 \mathrm{vol} \%$. These authors concluded and calculated that a monolayer with a thickness of $0.5 \mathrm{~nm}$ was formed at an IL pore filling degree of around $10 \mathrm{vol} \%$. The microand mesopores were successively blocked with increasing IL loadings.

SILP catalysis has not only been successfully applied for the immobilization of homogeneously dissolved transition metal complexes but also in acidic catalysis. Already in 2000 , the first example of an immobilized acidic chloroaluminate on a support has been reported by Hölderich for the alkylation of different aromatics (benzene, toluene, naphthalene and phenol) [86]. The acidic IL $\left[\mathrm{C}_{4} \mathrm{C}_{1} \mathrm{Im}\right] \mathrm{Cl} /$ $\mathrm{AlCl}_{3}$ was added to dried and calcined supports $\left(\mathrm{SiO}_{2}\right.$, $\mathrm{Al}_{2} \mathrm{O}_{3}, \mathrm{TiO}_{2}$ or $\mathrm{ZrO}_{2}$ ) and the excess of IL was extracted with DCM in a Soxhlet extraction system. Formation of $\mathrm{HCl}$ was observed during immobilization, indicating reaction of the chloroaluminate IL with the metal-OH groups of the support. Only the silica-based supports were active in the alkylation reaction. In 2002, the group of Hölderich published different covalent immobilization methods of acidic ionic liquids on porous supports [87]. Systems with both, covalently bound anions or cations to silica have been reported.

Joni et al. developed a well-defined and optimized pretreatment of silica support materials prior to impregnation with an acidic chloroaluminate IL [88]. A solution of $\mathrm{n}\left(\left[\mathrm{C}_{2} \mathrm{C}_{1} \mathrm{Im}\right] \mathrm{Cl}\right) / \mathrm{n}\left(\mathrm{AlCl}_{3}\right)=1 / 2$ and $\mathrm{DCM}$ was contacted with the calcined silica. After this chemical pretreatment step, surface $-\mathrm{OH}$ groups of the silica support were completely removed as the anion was covalently bound to the basic surface sites of the silica support. The pretreated supports themselves showed no catalytic activity in the investigated diisopropylbenzene isomerization reaction. The so surface-modified support was shown to give reproducible results after a further immobilization of a defined amount of acidic chloroaluminate IL. Pictures of this acidic SILP catalyst and the Lewis acidic IL $\mathrm{n}\left(\left[\mathrm{C}_{2}\right.\right.$ $\left.\left.\mathrm{C}_{1} \mathrm{Im}\right] \mathrm{Cl}\right) / \mathrm{n}\left(\mathrm{AlCl}_{3}\right)=1 / 2$ are shown in Fig. 3 .

In contrast to the work reported by Hölderich, this additional IL film remains free flowing on the support surface while being fixed to the support mainly by capillary forces and electrostatic interactions. These SILP catalysts were successfully tested in the slurry-phase Friedel-Crafts alkylation of cumene and in the continuous gas-phase isopropylation of cumene and toluene. The catalysts operated with constant high selectivity and unchanged catalytic activity for $210 \mathrm{~h}$ time-on-stream [88, 89].

\section{Solid Catalyst with Ionic Liquid Layer (SCILL)}

The main purpose of a Solid Catalyst with Ionic Liquid Layer (SCILL) systems is not to immobilize an IL, but to modify the catalytic reactivity of a solid surface. For this purpose, the internal surface of a classical heterogeneous catalyst is coated with a thin IL film. A schematic picture of a SCILL catalyst is shown in Fig. 4.

The following effects on the activity and selectivity of the solid catalyst have been observed through such IL coating:

- The IL coating may change the effective concentration of reactant(s), intermediate(s) and products at the solid catalytic site compared to the uncoated solid catalyst, according to the solubility of the gaseous reactants in the IL and related mass transfer processes [90];

- The IL may interact with the solid catalytic sites and thereby modify its adsorption and reaction properties [91, 92]; this includes the possibility that the IL may poison specific catalytic sites of the catalytic material thus suppressing unwanted side reactions [93]. Details will be given in Sect. 5 .

Jess and coworkers introduced the SCILL concept using a consecutive reaction as model transformation, the hydrogenation of cyclooctadiene to cyclooctene and cyclooctane $[90,94]$. A commercial $\mathrm{Ni} / \mathrm{SiO}_{2}$ catalyst was coated with the IL $\left.\left[\mathrm{C}_{4} \mathrm{C}_{1} \mathrm{Im}\right]\left[\mathrm{C}_{8} \mathrm{H}_{17} \mathrm{SO}_{4}\right]\right]$. The effect of the IL coating on the selectivity for the intermediate cyclooctene was very pronounced. One explanation for the much higher yield $(70 \%)$ of this intermediate when applying the SCILL catalyst as compared to the uncoated $\mathrm{Ni} / \mathrm{SiO}_{2}$ catalyst $(40 \%)$ is the lower solubility of the intermediate product which decreases the reaction rate for the consecutive hydrogenation. However, the influence of the IL layer on the effective concentrations of cyclooctadiene and cyclooctene alone could not explain the total change in selectivity. This hints to the fact, that the IL acts as a 
Fig. 3 Lewis acidic IL $\mathrm{n}\left(\left[\mathrm{C}_{2} \mathrm{C}_{1} \mathrm{Im}\right] \mathrm{Cl}\right) / \mathrm{n}\left(\mathrm{AlCl}_{3}\right)=1 / 2$ (left), acidic SILP catalyst $\mathrm{n}\left(\left[\mathrm{C}_{2} \mathrm{C}_{1} \mathrm{Im}\right] \mathrm{Cl}\right) / \mathrm{n}\left(\mathrm{AlCl}_{3}\right)=1 / 2$, immobilized on pretreated silica according to Joni [88] (right)
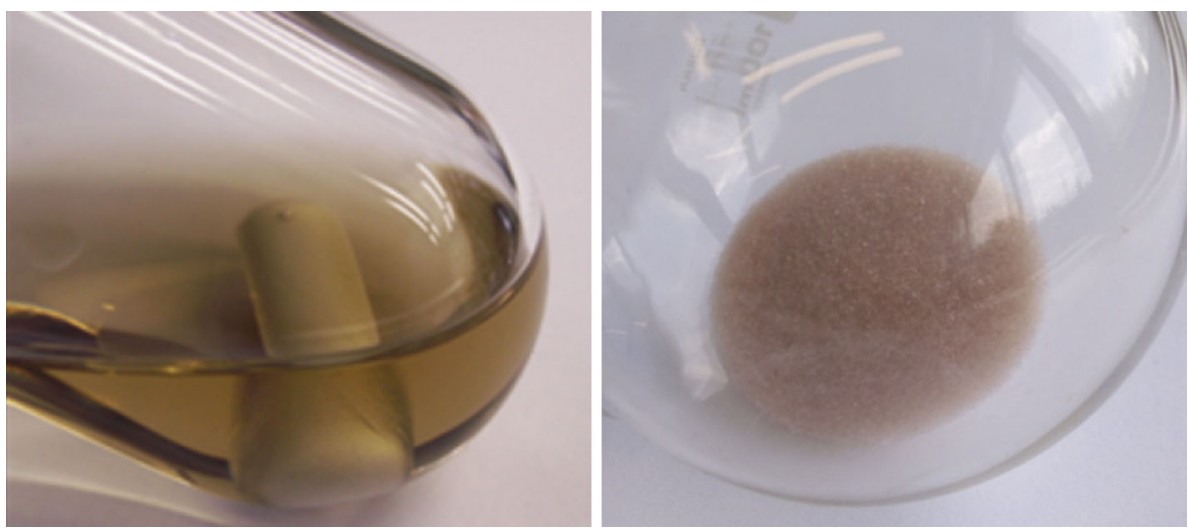

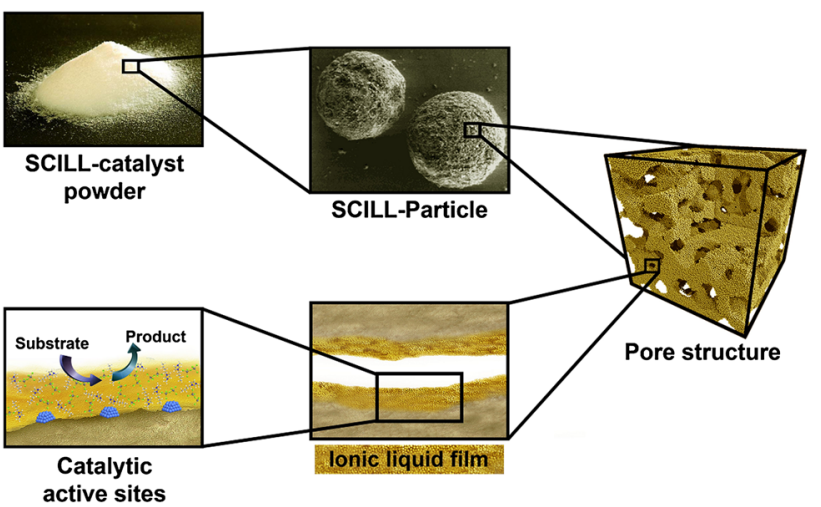

Fig. 4 SCILL catalyst materials-schematic view on a classical heterogeneous catalyst coated with a thin layer of ionic liquid

competing adsorbent and inhibits the (re)adsorption of cyclooctene on Ni sites. The IL coating also led to a decline in activity. Although, the SCILL catalyst was used in liquid phase catalysis, no leaching of the IL into the organic phase was detectable. The Jess group extended their SCILL research to further selective liquid and gas-phase hydrogenations [85]. For consecutive hydrogenation including reaction intermediates with lower solubility in the IL than the starting material (octene vs. octyne, hydrocinnamaldehyde vs. cinnamaldehyde, tetraline vs. naphthaline), the maximum yield of the intermediate increased by the IL coating compared to the uncoated catalyst.

The group of Claus investigated SCILL catalysts in the regioselective hydrogenation of citral [91, 95]. Supported Pd catalysts were coated with $\left[\mathrm{N}(\mathrm{CN})_{2}\right]^{-},\left[\mathrm{Tf}_{2} \mathrm{~N}\right]^{-}$, and $\left[\mathrm{PF}_{6}\right]^{-}$-based ILs. The modification of the applied Pd catalyst on silica by IL coating led to very high selectivities for citronellal, because consecutive and side reactions were inhibited effectively. The best results were achieved with $\left[\mathrm{N}(\mathrm{CN})_{2}\right]^{-}$-based ILs $(90 \%$ selectivity to citronellal at $80 \%$ conversion). The lower hydrogen solubility in ILs compared to organic solvents [96] did not influence the observed reaction rates in a negative manner. Further studies were conducted to investigate the interaction of the applied IL with the active Pd catalyst. Such investigations form the basis for a better molecular understanding of promoting effects in the citral hydrogenation [91] and other applications of SCILL catalysis. The coating of $\mathrm{Pd} / \mathrm{SiO}_{2}$ with ILs was shown to lower the hydrogen uptake and heats of adsorption remarkably. The reduction of $\mathrm{H}_{2}$ uptake was much higher for $\left[\mathrm{N}(\mathrm{CN})_{2}\right]^{-}$-based ILs compared to $\left[\mathrm{Tf}_{2} \mathrm{~N}\right]^{-}$-based ILs. X-ray photoelectron spectroscopy (XPS) measurements revealed that ILs deposited on Pd/ $\mathrm{SiO}_{2}$ modify the chemical state of surface $\mathrm{Pd}$ which is partially transformed to $\mathrm{Pd}^{2+}$ and undergoes complexation with the $\left[\mathrm{N}(\mathrm{CN})_{2}\right]^{-}$. The IL anion acts as ligand to the metal. This finding was also underlined by IR spectroscopy. Surface science studies related to these topics are highlighted in Sect. 5. Selective citral hydrogenation with Pd-based SCILL catalysts using the $\mathrm{IL}\left[\mathrm{C}_{4} \mathrm{C}_{1} \mathrm{Im}\right]\left[\mathrm{N}(\mathrm{CN})_{2}\right]$ was also applied continuously in a trickle-bed reactor [97].

Silica-supported Pt catalysts with a thin film of 1-butyl2,3-dimethylimidazolium trifluoromethane-sulfonate $\left(\left[\mathrm{C}_{4}\right.\right.$ dmIm][TfO]) were investigated by the Lercher group with focus on the interactions between IL, support and Pt particles [84]. Interaction of silica and IL occurs via hydrogen bonds. Pt clusters modify the electron density of the IL, which changes its polarity within certain levels. The IL protects the Pt cluster from oxidation as the Pt particles in IL-coated systems are in zero oxidation state. SCILL-catalyzed ethene hydrogenation showed that the interaction of the IL and the Pt surface is weaker than the interaction of ethylene and the Pt surface.

Since the first reports on SILP and SCILL catalysis, the industrial interest in these two technologies has been very high. Both technologies aim to realize beneficial IL features in catalysis with the smallest possible amount of IL and thus in a most efficient manner. This greatly reduces the IL-specific investment and all potential IL-related risk that scale with the applied quantity of IL. Moreover, the immobilization of the IL on a solid support limits the ILrelated risk to a small section of the overall plant. To 
Table 2 Comparison of catalysis with SILP and SCILL systems

\begin{tabular}{|c|c|c|}
\hline & SILP & SCILL \\
\hline Catalyst nature & $\begin{array}{l}\text { Homogeneous metal catalyst dissolved in } \\
\text { an ionic liquid and immobilized on } \\
\text { porous support }\end{array}$ & $\begin{array}{l}\text { Heterogeneous catalyst coated } \\
\text { with ionic liquid }\end{array}$ \\
\hline Purpose & Immobilization of homogeneous catalyst & $\begin{array}{l}\text { Modification of heterogeneous catalyst, } \\
\text { activity and/or selectivity improvement }\end{array}$ \\
\hline Reactant/product solubility & Optimal: high for reactants, low for products & Optimal: high for reactants, low for products \\
\hline Ionic liquid loading & $\begin{array}{l}\text { Low for high specific surface area, but enough for } \\
\text { homogeneous dissolution of metal (complex) }\end{array}$ & $\begin{array}{l}\text { Low for high specific surface area but } \\
\text { enough to cover active sites }\end{array}$ \\
\hline Ionic liquid-support interaction & Good wettability required & Good wettability required \\
\hline Metal and metal complex solubility & As high as possible & As low as possible \\
\hline Ionic liquid-metal interaction & Desired to stabilize catalyst in solution & Desired to enhance activity and / or selectivity \\
\hline Maximum reaction temperature & $\begin{array}{l}\text { Limited by stability of metal (complexes) } \\
\text { and ligand }\end{array}$ & Limited by ionic liquid stability \\
\hline
\end{tabular}

summarize SILP and SCILL catalysis, a comparison of characteristic features of these two ionic liquid thin film technologies is given in Table 2. The table is intended to highlight important differences and some similarities. Note that examples can also be found in literature that combine the idea of SILP and SCILL catalysis, e.g. by using solvent-born particles stabilized by a supported IL film [98].

\section{Molecular Insights into IL/Gas and IL/Support Interfaces}

In both the SILP and the SCILL concept, the importance of the interface of the IL with its environment (solid, liquid or gaseous) has been recognized, and consequently the surface and interface properties of ILs as well as related processes have received strongly increasing attention recently [99-108]. In particular, a detailed molecular level understanding nowadays is considered as indispensable for predicting macroscopic surface and interface properties. Due to the unbalanced forces resulting from the non-isotropic environment, the composition of the near-interface region and the arrangement of cations and anions at the interface can be very different to that in the bulk. Surface termination, orientation of the outermost species (or end groups of larger anions or cations), segregation effects, surface contaminations, etc. are only some of the most relevant aspects to be addressed at the IL/vacuum (IL/gas) interface. The same holds true for the IL/solid interface, where specific support-IL interactions come into play. From these considerations, it is evident that investigations of the surface and interface properties of ILs, at an atomic level accuracy, are of the same pivotal importance as for the solid/gas interface of classical heterogeneous catalysts.

IL surface properties have been investigated by numerous surface-sensitive spectroscopic techniques and scattering methods. Initially, these studies were mainly restricted to methods that can be applied under ambient conditions, such as sum-frequency generation (SFG) [100, 109-116], X-ray reflectivity and neutron reflectometry [112, 117-121], grazing incidence X-ray diffraction [122], atomic force microscopy (AFM) [104, 123-134] and surface force balance (SFB) [135-137]. In 2005, it was realized that the surface properties of ILs can also be investigated using the well-developed techniques of "classical" surface science. While these techniques typically are restricted to the investigation of solid substrates under ultra-high vacuum (UHV) conditions, the low IL vapour pressure (typically $<10^{-9}$ mbar for aprotic ILs at room temperature) enables the investigations of these liquids under UHV. In the meantime, this new field of "Ionic Liquid Surface Science" is one important subdiscipline in ongoing IL research [102]. Many established UHV-based surface science techniques have successfully contributed to an increasingly detailed understanding not only of the IL/ vacuum interface, but also of IL bulk properties. The applied methods include X-ray photoelectron spectroscopy (XPS) [106, 107, 138-164], UV photoelectron spectroscopy $[138,139,165,166]$, inverse photoelectron spectroscopy (IPES) [165, 166], X-ray absorption spectroscopy (NEXAFS) [165], soft X-ray emission spectroscopy (SXES) [166], low energy ion scattering (LEIS) [141], metastable ion spectroscopy (MIES) [138, 139], time-offlight secondary mass spectroscopy (TOF-SIMS) [140], Rutherford backscattering [167-171], high resolution electron energy loss spectroscopy (HREELS) [138], reflection absorption infrared spectroscopy (RAIRS) [172175], direct recoil spectroscopy (DRS) [176], and scanning tunneling microscopy [177-181], to name only a few. In addition, an increasing number of theoretical studies and simulations have been conducted [101, 182-190]. The easy access to the liquid-vapour interface of ILs under UHV 
conditions has also opened a new era for the spectroscopic investigation of liquid surfaces in general [102].

Herein, we concentrate on results, which were obtained by XPS. XPS allows for the quantitative analysis of the chemical composition of the surface-near region, and is thus also denoted as electron spectroscopy for chemical analysis (ESCA). The sensitivity of the core-level binding energy of a particular atom to its chemical environment and oxidation state is reflected in the so-called "chemical shift". Since the first XPS studies of ILs about 10 years ago, numerous neat or functionalised ILs and IL solutions were examined, and it was demonstrated that XPS is a most powerful method to investigate the IL/vacuum interface [107, 108, 138-164]. In particular by angle resolved XPS (ARXPS), the near-surface region can be quantitatively analysed with high accuracy [106-108, 145, 175, 191]. The obtained information ranges from the surface chemical composition of the IL, molecular orientation of cations and anions at the IL/vacuum interface, surface enrichment effects and surface contaminants to the IL bulk composition and the chemical state of dissolved catalyst ions (e.g., dissolved metal complexes). In 2008, it was realized that ultrathin IL films with thicknesses ranging from the submonolayer range to some ten monolayers can be prepared by physical vapour deposition (PVD) using simple Knudsen cells $[150,151,192]$. While this approach is restricted to ILs, which can be evaporated as intact ion pairs, it was shown very recently that less stable ILs, which decompose upon heating, can be deposited intact using electrospray ionization deposition (ESID) [164]. PVD and ESID preparation methods enable the application of UHV-based analysis techniques now also for studying the IL/support interface under well-defined conditions, which is of highest relevance of SCILL applications. The first studies by ARXPS demonstrated that the adsorption and wetting behaviour strongly depend on the particular combination of IL and support, with a strong influence of contaminations $[150,156,192]$. Furthermore, it was demonstrated that XPS can be also used to study reactions in ILs or at ILsubstrate or IL-electrode interfaces in situ, as a function of time or temperature [148, 161, 162, 173, 193-200].

To illustrate the state of the art of ionic liquid surface science, some specific aspects, which are relevant for SILP and SCILL catalysis will be addressed in the following. When studying IL/gas or IL/vacuum interfaces, typically macroscopic films of ultra clean ILs or IL solutions with thicknesses of about $0.1-0.5 \mathrm{~mm}$ were prepared ex situ on a planar Au foil $\left(20 \times 15 \times 0.1 \mathrm{~mm}^{3}\right)$ and then introduced into the UHV system via a loadlock. The ARXPS measurements were performed using Al-K $\alpha$ radiation $(1486.6 \mathrm{eV})$. In ARXPS, the surface sensitivity varies with electron emission angle [107, 143]: Measurements at normal emission, i.e. at $\vartheta=0^{\circ}$ relative to the surface normal, probe the near-surface region with an information depth, ID: 7-9 nm (depending on the kinetic energy); measurements at grazing emission, i.e. at $\vartheta=80^{\circ}$, probe the topmost surface layers, with an ID: $1-1.5 \mathrm{~nm}$; the ID is defined as 3 times the inelastic mean free path length of the electron in a material at a given kinetic energy, with $95 \%$ of the measured signal originating from this depth range. The high surface sensitivity at $80^{\circ}$ allows deriving information on the surface composition and on the arrangement of the molecules in the topmost layer. For a homogenous distribution of one element in an investigated sample, identical intensities of the corresponding core levels are expected at all emission angles [107]. An increased signal at $80^{\circ}$ (that is, in the surface sensitive geometry), indicates an enrichment of this element in the topmost layers as compared to the bulk; correspondingly, a decreased signal at $80^{\circ}$ indicates a depletion of this element in the topmost layers. Deviations of the surface composition from that in the bulk can be due to a pronounced preferential orientation of cations or anions in the IL, due to surface enrichment or depletion of one component in a mixture or a solution of ILs, but also due to the surface enrichment of contaminations [142, 147].

In the following exemplary results concerning the IL/ vacuum or IL/gas interface, the solubility and surface enrichment of dissolved metal complexes, the IL/support interface and the in situ monitoring of chemical reactions in ILs are summarized.

\subsection{IL Surface Composition, Orientation and Enrichment}

\subsubsection{Surface Orientation}

Depending on the nature of the IL, pronounced orientation effects are observed at the IL/vacuum interface. An instructive example is 1-methyl-3-octylimidazolium 4-chlorobutylsufonate $\left(\left[\mathrm{C}_{8} \mathrm{C}_{1} \mathrm{Im}\right]\left[\mathrm{ClC}_{4} \mathrm{H}_{8} \mathrm{SO}_{3}\right]\right)[107,148]$ : In Fig. 5, the relevant XP spectra of a $\sim 100 \mu \mathrm{m}$ thick film are shown for emission angles of $0^{\circ}$ (black) and $80^{\circ}$ (green), that is, for the bulk- and surface-sensitive geometries, respectively.

For the anion, the spin-orbit split $\mathrm{Cl} 2 \mathrm{p}_{1 / 2}$ and $2 \mathrm{p}_{3 / 2}$ levels strongly increase when changing from $0^{\circ}$ to $80^{\circ}$, which indicates an enrichment of the chlorine at the outer surface. On the other hand, the $\mathrm{O} 1 \mathrm{~s}$ and also the $\mathrm{S} 2 \mathrm{p}$ peaks (not shown) decrease when changing from $0^{\circ}$ to $80^{\circ}$, which indicates the depletion of these atoms from the outer surface. This behaviour results from a pronounced preferential orientation of the anion, such that the chlorobutyl chain points towards the vacuum side and the sulfonate group towards the bulk. For the cation, the imidazolium $\mathrm{N} 1 \mathrm{~s}$ signal is significantly smaller at $80^{\circ}$, whereas the $\mathrm{C} 1 \mathrm{~s}$ signal of the octyl chain at $285.1 \mathrm{eV}$ is enhanced, as compared to $0^{\circ}$. These changes result from a preferential 

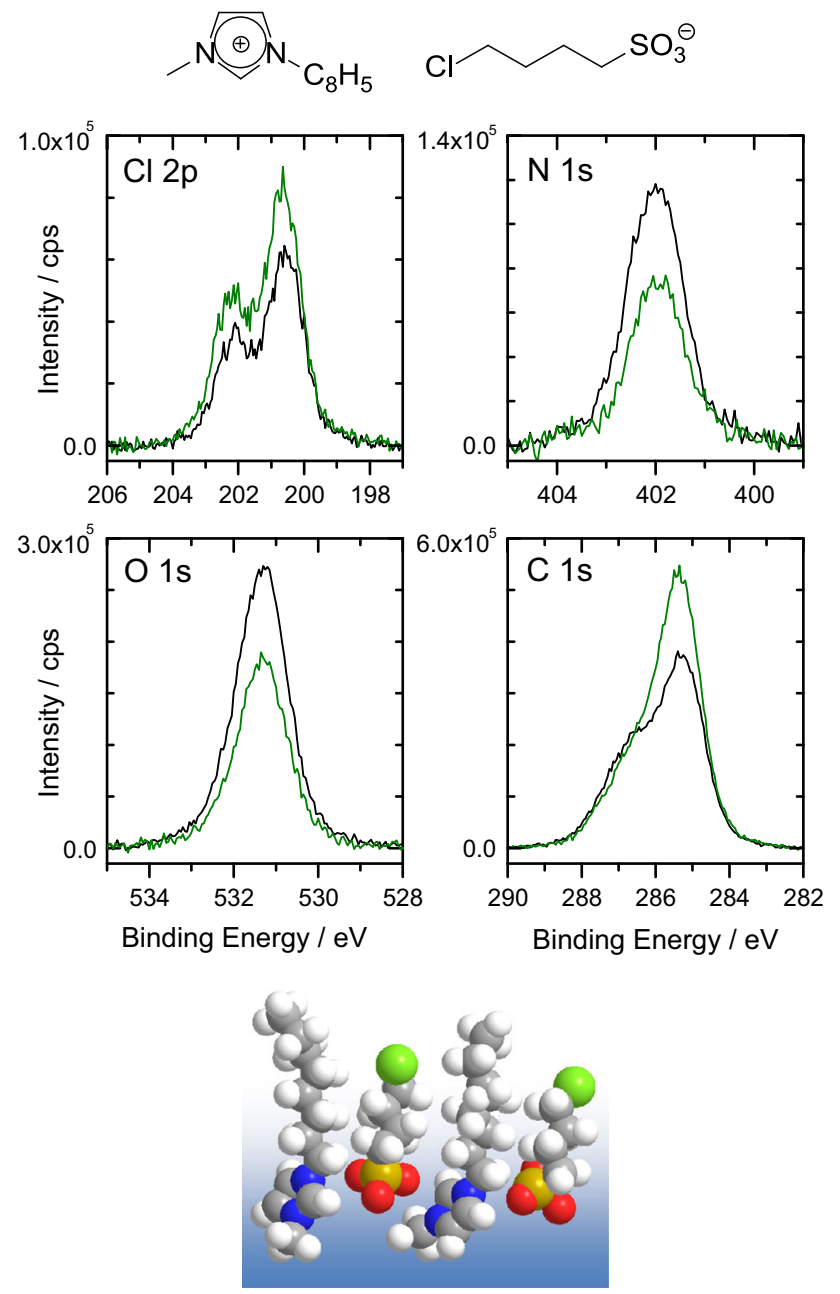

Fig. 5 AR-XPS of $\left[\mathrm{C}_{8} \mathrm{C}_{1} \mathrm{Im}\right]\left[\mathrm{ClC}_{4} \mathrm{H}_{8} \mathrm{SO}_{3}\right]$ at $0^{\circ}$ (black) and $80^{\circ}$ (green). The schematic illustration indicates the orientation of cation and anion in the outermost surface layer; colour-code: $\mathrm{Cl}$ (green), $\mathrm{N}$ (blue), S (yellow), O (red), C (grey) and $\mathrm{H}$ (white). Reproduced from Ref. [107] with permission from the PCCP Owner Societies

orientation of the $\left[\mathrm{C}_{8} \mathrm{C}_{1} \mathrm{Im}\right]^{+}$cations at the outer surface, with the octyl chains pointing towards the vacuum, and the imidazolium ring positioned underneath. The charged head-groups of cation and anion are located at about the same distance below the outer surface, which is deduced from the comparable decrease of the $\mathrm{N} 1 \mathrm{~s}$ and $\mathrm{O} 1 \mathrm{~s}$ signals at $80^{\circ}$ as compared to $0^{\circ}$. The deduced arrangement of the IL at the outer surface is schematically shown at the bottom of Fig. 5 [107, 148].

\subsubsection{Surface Composition and Enrichment Effects}

To systematically study surface enrichment effects, seven ILs with alkyl chains of different length $\left[\mathrm{C}_{n} \mathrm{C}_{1} \operatorname{Im}\right]\left[\mathrm{Tf}_{2} \mathrm{~N}\right]$, with $n=2$ to 16 , were studied by ARXPS [107, 143, 152]. To analyse the enrichment of the alkyl chain, the intensity ratio of the $\mathrm{C} 1 \mathrm{~s}$ signals of the alkyl chain and of the cation

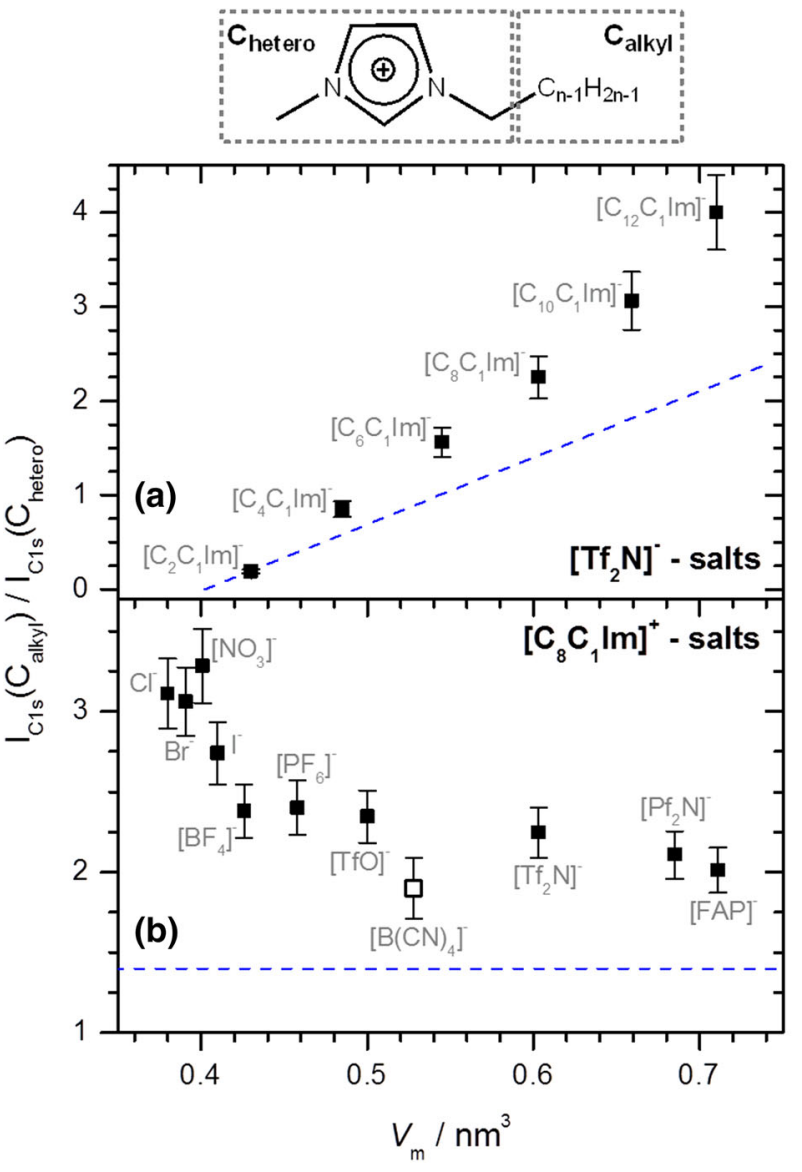

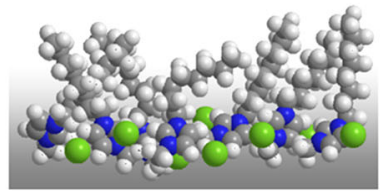

$\left[\mathrm{C}_{8} \mathrm{C}_{1} \operatorname{lm}\right] \mathrm{Cl}$

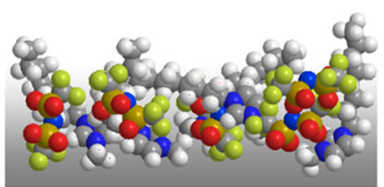

$\left[\mathrm{C}_{8} \mathrm{C}_{1} \operatorname{lm}\right]\left[\mathrm{Tf}_{2} \mathrm{~N}\right]$
Fig. $6 \mathrm{C}_{\text {alkyl }} / \mathrm{C}_{\text {hetero }}$ intensity ratio, measured at $80^{\circ}$ as a function of IL molecular volume $V_{\mathrm{m}}$ : a seven ILs with the same anion, but cations with alkyl chains of different length, $\left[\mathrm{C}_{\mathrm{n}} \mathrm{C}_{1} \mathrm{Im}\right]\left[\mathrm{Tf}_{2} \mathrm{~N}\right]$, with $\mathrm{n}=2$ to 16 ; b ten ILs with the same cation $\left[\mathrm{C}_{8} \mathrm{C}_{1} \mathrm{Im}\right]^{+}$but different anions. The schematic illustration at the bottom shows the different degree of packing (enrichment) of the alkyl chain for the small $[\mathrm{Cl}]^{-}$anions (left) as compared to the larger $\left[\mathrm{Tf}_{2} \mathrm{~N}\right]^{-}$anion (right). Reproduced from Ref. [107] with permission from the PCCP Owner Societies

headgroup, $\mathrm{I}_{\mathrm{C} 1 \mathrm{~s}}\left(\mathrm{C}_{\mathrm{alky1}}\right) / \mathrm{I}_{\mathrm{C} 1 \mathrm{~s}}\left(\mathrm{C}_{\text {hetero }}\right)$, for different chain lengths, $n$, is plotted in Fig. $6 \mathrm{a}$, as function of molecular volume. The measurements were performed at $80^{\circ}$, i.e., in the surface sensitive geometry; the dashed line corresponds to the nominal composition. For short chain lengths, the measured ratios (square symbols) coincide with the dashed line, indicating an isotropic arrangement at the outer surface. However, for larger chains lengths, the observed ratios are significantly above the dashed line. This behaviour reflects an enrichment of the alkyl chains at the outer 
surface, which increases with increasing chain length. From the analysis of the other IL core levels, it was deduced that anions and cationic head groups are located approximately at the same distance from the outer surface, with the anion slightly above the imidazolium ring. In line with other related studies and corresponding calculations it was concluded that the alkyl chains in the topmost surface layer point towards the vacuum, similar as known for longchain self-assembled mono-layers [145, 183, 186, 201]. Furthermore, the surface composition derived from XPS was found to correlate very well to conclusions from macroscopic surface tension measurements; the latter show an initial decrease of the surface tension with alkyl chain length to a constant value starting at $\mathrm{n}=8$, i.e., for a chain length, where the outer surface is already completely composed of alkyl groups [202].

\subsubsection{Influence of the Anion on Surface Enrichment}

The effect of the anion on the surface enrichment was studied for ten ILs with the same cation $\left[\mathrm{C}_{8} \mathrm{C}_{1} \mathrm{Im}\right]^{+}$but different anions; the anions were chosen to cover different sizes, shapes (from spherical to elongated), basicities and coordination abilities (from strongly coordinating halides to weakly coordinating anions with perfluoroalkyl groups) [107, 143, 146]. They included $\mathrm{Cl}^{-}, \mathrm{Br}^{-}, \mathrm{F}^{-},\left[\mathrm{NO}_{3}\right]^{-},\left[\mathrm{BF}_{4}\right]^{-},\left[\mathrm{PF}_{6}\right]^{-},[\mathrm{TfO}]^{-}$, $\left[\mathrm{Tf}_{2} \mathrm{~N}\right]^{-}, \quad\left[\left(\mathrm{C}_{2} \mathrm{~F}_{5} \mathrm{SO}_{2}\right)_{2} \mathrm{~N}\right]^{-}\left(\left[\mathrm{Pf}_{2} \mathrm{~N}\right]^{-}\right)$and $\left[\mathrm{PF}_{3}\left(\mathrm{C}_{2} \mathrm{~F}_{5}\right)_{3}\right]^{-}$ $\left([\mathrm{FAP}]^{-}\right)$. In order to compare the degree of surface enrichment in the different ILs, the ratio $\mathrm{I}_{\mathrm{C} 1 \mathrm{~s}}\left(\mathrm{C}_{\mathrm{alkyl}}\right) / \mathrm{I}_{\mathrm{Cls}}\left(\mathrm{C}_{\text {hetero }}\right)$ for ARXPS measurements at $80^{\circ}$ is plotted in Fig. $6 \mathrm{~b}$ as a function of molecular volume. The ratios for all ILs are significantly larger than the nominal value (dashed line), with the magnitude of the deviation decreasing with increasing molecular volume. This behaviour indicates surface enrichment of the alkyl chains for all studied ILs, with the degree of enrichment being more pronounced for the smaller anions $\mathrm{Cl}^{-}, \mathrm{Br}^{-}$and $\left[\mathrm{NO}_{3}\right]^{-}$, and less prominent for the larger anions $\left[\mathrm{Pf}_{2} \mathrm{~N}\right]^{-}$and $[\mathrm{FAP}]^{-}$. The higher degree of enrichment for the small anions is mainly attributed to their smaller size and stronger interaction between the polar groups which leads to the formation of a more densely packed and better oriented surface layer [107, 143, 146].

\subsubsection{Influence of Functional Units}

To investigate the effect of functional units on surface orientation and enrichment, a systematic ARXPS study was performed [160]. It addressed a variety of functionalized and also some non-functionalized ILs, including imidazolium-based ILs methylated at the $\mathrm{C}(2)$ position, a phenylfunctionalized IL, an alkoxysilane-functionalized IL, halofunctionalized ILs, thioether-functionalized ILs, and amine-functionalized ILs. Overall, the occurrence of surface enrichment of functional groups/chains and also non-functional alkyl chains was found to depend on the interplay/competition of the interactions between the ionic headgroups, dispersive interactions between the ionic headgroups and the chains/functional units, and dispersive interactions between the chains/functional units. The following general trends were deduced [160]:

- For weak interactions between the functional units/ chains and the headgroups, typically surface enrichment of the functional groups/chains is observed when the chain is sufficiently long $(n>4)$; examples are imidazolium-based ILs with non-functionalized, halogen-functionalized, alkoxysilane-functionalized, thioether-functionalized and amine-functionalized alkyl chains. These effects are found for functional groups attached to the cation and also the anion headgroups. For short chains $(\mathrm{n}<4)$, i.e. chloro- or iodoethyl, no such enrichment is found.

- In case of significant interactions between functional groups and ionic headgroups, e.g. through hydrogenbonding for ether groups or quadrupol-interactions for phenyl groups, surface enrichment of the functional chains is suppressed, in contrast to the behaviour for non-functional chains of the same length.

- In case of surface enrichment of the functional groups/ chains, the cationic and anionic headgroups typically form a polar layer underneath, at the same or a very similar distance to the outer surface.

- For ILs with functionalized/non-functionalized chains both at the anion and the cation (e.g. $\left[\mathrm{C}_{12} \mathrm{C}_{1} \mathrm{Im}\right]$ $\left[\mathrm{FC}_{4} \mathrm{H}_{8} \mathrm{SO}_{3}\right]$ ), a surface arrangement is observed with both chains pointing towards the vacuum; if the chains have different lengths, the end-group (e.g., the F atom) of the shorter chain is not at the outer surface.

- Dispersive interactions between the functional groups/ chains both at anions and cations contribute to an enhanced surface enrichment. Thus double-functionalized ILs with short functionalized chains at the anion and the cation, e.g. $\left[\left(\mathrm{HOC}_{2} \mathrm{H}_{4}\right)_{2} \mathrm{Me}_{2} \mathrm{~N}\right]\left[\mathrm{H}_{2} \mathrm{NC}_{2} \mathrm{H}_{4} \mathrm{SO}_{3}\right]$, show an enrichment of both functional groups.

- Independent of the occurrence of surface enrichment of the cation, for all studies with $\left[\mathrm{Tf}_{2} \mathrm{~N}\right]^{-}$anions, the latter show a preferential surface orientation in cis-conformation, with its $\mathrm{CF}_{3}$ groups pointing towards the vacuum and its $\mathrm{SO}_{2}$ groups pointing towards the bulk.

\subsection{Dissolution of Catalysts in ILs}

In the SILP concept, where the catalyst is dissolved in a supported IL layer, reactants have to pass the surface, diffuse to the active complex, react there, diffuse back to and pass through the surface again. If the catalyst is preferentially 
enriched in the near surface region, the diffusion pathways are reduced and the total process is more efficient. In one of the first ARXPS studies, it was shown that the transition metal salt $\left[\mathrm{Pt}\left(\mathrm{NH}_{3}\right)_{4}\right] \mathrm{Cl}_{2}$, with a nominal bulk concentration below $0.1 \mathrm{~mol} \%$ dissolved in $\left[\mathrm{C}_{2} \mathrm{C}_{1} \mathrm{Im}\right]\left[\mathrm{EtOSO}_{3}\right]$ exhibited a strongly enhanced concentration of the $\left[\mathrm{Pt}\left(\mathrm{NH}_{3}\right)_{4}\right]^{2+}$ cation in the surface layer whereas the $\mathrm{Cl}^{-}$counterion is surface-depleted [203]. The obvious challenge concerning such surface enrichment effects is to understand the physical and chemical properties to an extent which allows for selective tuning of the IL and/or the catalyst properties to achieve a desired enrichment (or in other cases depletion) [161]. One first successful idea in this context was the introduction of surface active ligands: When adding $\mathrm{Rh}(\mathrm{acac})(\mathrm{CO})_{2}$ to a saturated solution of the ligand tppts dissolved in $\left[\mathrm{C}_{2} \mathrm{C}_{1-}\right.$ $\mathrm{Im}]\left[\mathrm{EtOSO}_{3}\right]$, a maximum concentration of $5.1 \mathrm{~mol} \% \mathrm{Rh}$ in the IL was achieved as compared to $0.19 \mathrm{~mol} \%$ without the tppts ligand [155]. This induced increase of the Rh concentration was a strong indication for the in situ transformation of the Rh-complex in the polar IL solution by the coordination of the tppts ligand. Furthermore, the nature of the applied ligand was found to influence the preferred position of the catalyst complex in either the bulk phase or at the surface. The formed Rh-tppts complex proved to exhibit significant surface activity in $\left[\mathrm{C}_{2} \mathrm{C}_{1} \mathrm{Im}\right]\left[\mathrm{EtOSO}_{3}\right]$, as compared to an analogous tppts-free system, where for the same Rh-precursor even Rh-depletion from the surface was found [155]. These data are in line with molecular dynamics studies by Sieffert and Wipff who claimed significant interface (surface) activity of Rh-tppts complexes in organic/ionic liquid (vacuum/IL) multiphase systems [189].

\subsection{IL/Solid Interfaces}

For SCILL, the interaction of the IL with the supported catalyst and also with the support itself is of highest relevance. This interaction depends on the specific properties of IL and surface; it determines, how cations and anions are arranged at the interface and whether the IL will grow layerby-layer as two-dimensional film, or as three-dimensional islands. This wetting or non-wetting behaviour, respectively, at the liquid/solid interface is important not only for heterogeneous catalysis but also for other applications, such as e.g. electrode or membrane wetting in electrochemistry or surface wetting in lubrication [99, 100, 204-206]. Investigations of the IL/solid interface can be categorized in two types: (1) Studies carried out at the IL/solid interface below a macroscopically thick IL film, mostly by using methods that do not rely on ultrahigh vacuum $[110,114-116,118,123$, 128-132, 207-215]. For such films, the interface is not accessible by XPS, due to damping of the interface signals by the IL film. (2) For ILs that can be evaporated intact (that is as neutral ion pairs [216]), the preparation of ultrathin IL films by physical vapour deposition under well-controlled and clean UHV conditions is possible [150, 156, 192]. A second promising concept is electrospray ionization deposition (ESID), which enables even the deposition of less stable ILs onto solid surfaces [164]. Based on these new preparation methods, the detailed characterization of the initial growth stages, the arrangement of the ions at the IL/support interface, the electronic interactions between IL and support, and the thermal stability is possible nowadays $[150,163,164$, $173,175,179-181,192,200,205,215,217]$. In the following, several examples will be discussed in order to demonstrate, how sensitive the observed behaviour depends on the specific combination of IL and substrate. Specifically, we address $\left[C_{n} C_{1} \operatorname{Im}\right]\left[\mathrm{Tf}_{2} \mathrm{~N}\right]$ layers $(n=1,8)$ on $\mathrm{Au}(111)$ [192] and $\mathrm{Ni}(111)$ [156]. We first discuss the behaviour of the IL in the first layer, i.e., the initial stages of film formation. Thereafter, the successive growth on top of this first wetting layer is addressed.

On $\mathrm{Au}(111)$, a checkerboard-type arrangement was deduced from ARXPS measurements for the first layer of $\left[\mathrm{C}_{1} \mathrm{C}_{1} \operatorname{Im}\right]\left[\mathrm{Tf}_{2} \mathrm{~N}\right]$ and also $\left[\mathrm{C}_{8} \mathrm{C}_{1} \operatorname{Im}\right]\left[\mathrm{Tf}_{2} \mathrm{~N}\right]$ (from low coverage on); in this layer, cation and anion are adsorbed next to each other, both in direct contact to the surface [192]; see Fig. $7 \mathrm{a}$ for $\left[\mathrm{C}_{1} \mathrm{C}_{1} \operatorname{Im}\right]\left[\mathrm{Tf}_{2} \mathrm{~N}\right]$. For $\left[\mathrm{C}_{8} \mathrm{C}_{1} \operatorname{Im}\right]\left[\mathrm{Tf}_{2} \mathrm{~N}\right]$, a reorientation of the alkyl chain with increasing coverage is found, such that the chain points away from the surface.

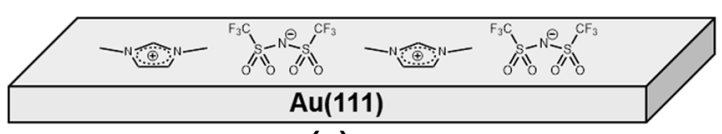

(a)

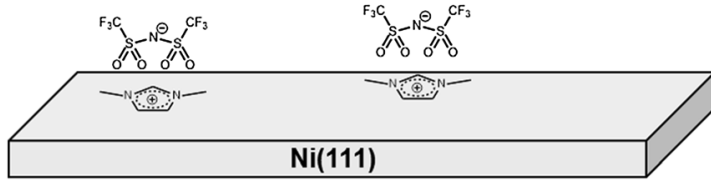

(b)

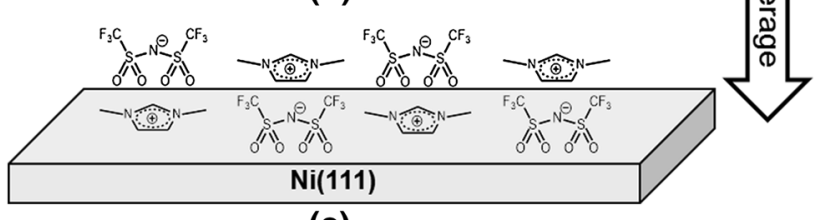

(c)

Fig. 7 Sketch of the growth of $\left[\mathrm{C}_{1} \mathrm{C}_{1} \mathrm{Im}\right]\left[\mathrm{Tf} \mathrm{f}_{2} \mathrm{~N}\right]$ on different surfaces. a On $\mathrm{Au}(111)$, cations and anions are adsorbed next to each other, forming a checkerboard-type structure from low coverage up to complete coverage of the surface; $\mathbf{b}$ on $\mathrm{Ni}(111)$, at low coverage, cations are in contact with the substrate with anions on top, i.e. ion pairs form a sandwich-type structure. $\mathbf{c}$ on $\mathrm{Ni}(111)$, at saturation of the first layer, a checkerboard-type sandwich structure is formed, with neighbouring sandwiches having an opposite orientation (i.e. either cation or anion in contact with the surface). The driving force for the change in structure with increasing coverage between $\mathbf{b}$ and $\mathbf{c}$ is repulsive dipole interaction between the sandwiches with the same orientation (see text). Note that in $\mathbf{c}$ twice the amount of IL is required to completely cover the surface than in a 
This type of arrangement was also found by scanning tunnelling microscopy and XPS for a similar $\mathrm{IL},\left[\mathrm{C}_{4} \mathrm{C}_{1}\right.$ Pyrr] $\left[\mathrm{Tf}_{2} \mathrm{~N}\right]$, on $\mathrm{Au}(111)$; in the STM images of the first completed layer, even a high degree of long range order of alternating cations and anions was observed at low temperature $(100-120 \mathrm{~K})$, and the orientation of the $\mathrm{C}_{4}$ chains towards the vacuum side was confirmed [217]. On Ni(111), a very different behavior is observed for $\left[\mathrm{C}_{1} \mathrm{C}_{1} \operatorname{Im}\right]\left[\mathrm{Tf}_{2} \mathrm{~N}\right]$ : At submonolayer coverages $(<0.4$ monolayer $)$, the IL adsorbs in a bilayer (or sandwich)-type structure, with the cation in direct contact to the surface and the anion above it; see Fig. 7 b. Starting at 0.55 monolayers, a transition to a checkerboard-type "sandwich" structure is found, with alternating orientations of neighboring sandwiches [156]; see Fig. 7c. This transformation is attributed to repulsive dipole-dipole interactions of neighbouring ion pairs with the same orientation. With increasing surface coverage, these repulsive interactions increase due to the lower intermolecular distances, and at a critical coverage, the checkerboard-type "sandwich" structure becomes energetically favourable, since in this arrangement the interactions of oppositely oriented next-neighbour ion pairs are attractive [156]. On $\mathrm{Ni}(111)$, the IL was found to desorb intact upon heating to at temperatures as low as $400 \mathrm{~K}$, which indicates a rather weak interaction. In contrast, partial IL decomposition is found upon heating on oxidised $\mathrm{Ni}(111)$ [156].

Next, we address the further growth behaviour on top of the first, so-called, wetting layer. The information on the growth mode is obtained from the attenuation of the substrate signal at emission angles of $0^{\circ}$ and $80^{\circ}$, as a function of the amount of deposited IL. The observed behaviour strongly depends on the specific IL substrate combination: While for $\left[\mathrm{C}_{8} \mathrm{C}_{1} \mathrm{Im}\right]\left[\mathrm{Tf}_{2} \mathrm{~N}\right]$ on $\mathrm{Au}(111)$ [192], layer-bylayer growth is observed up to $\sim 10$ layers (for larger thicknesses no conclusions can be derived from ARXPS), for $\left[\mathrm{C}_{8} \mathrm{C}_{1} \mathrm{Im}\right] \mathrm{Cl}$ on $\mathrm{Au}(111)$ [164], three-dimensional island growth starts immediately after completion of the first layer. Interestingly, the structure of the first wetting layer, i.e. a checkerboard arrangement with the cationic imidazolium ring and the anion adsorbed next to each other on the substrate and the alkyl chain pointing toward vacuum, was the same for both ILs [164]. This dramatic difference in growth mode of the two ILs on the same substrate was attributed to differences in the cation-anion interactions and in the degree of order in the wetting layer of the two ILs. Note that in this study IL deposition was carried out by ESID, as $\left[\mathrm{C}_{8} \mathrm{C}_{1} \mathrm{Im}\right] \mathrm{Cl}$ would decompose upon evaporation [164]. The growth mode of $\left[\mathrm{C}_{1} \mathrm{C}_{1} \operatorname{Im}\right]\left[\mathrm{Tf}_{2} \mathrm{~N}\right]$ on the checkerboard-type sandwich structure on $\mathrm{Ni}(111)$ [156] and also for $\left[\mathrm{C}_{2} \mathrm{C}_{1} \operatorname{Im}\right]\left[\mathrm{Tf}_{2} \mathrm{~N}\right]$ on glass [150] occurs in threedimensional islands. Finally, ARXPS measurements of the growth of $\left[\mathrm{C}_{1} \mathrm{C}_{1} \mathrm{Im}\right]\left[\mathrm{Tf}_{2} \mathrm{~N}\right]$ on freshly air-cleaved mica surfaces showed a pronounced dependence of the initial IL adsorption behaviour on carbon precoverages: On clean mica, 3D growth (complete dewetting) occurs, whereas on a fully carbon-covered surface, initially a complete 2D wetting layer forms, followed by 3D growth [163].

\subsection{In Situ Reaction Monitoring}

Traditionally, XPS was only used to study reactions occurring on solid surfaces in situ. This was due to the high vapour pressures of common liquids or solvents, which are not compatible with the required UHV conditions. It was only recently realized that the situation is very different, when studying reactions in ILs, which have an inherently low vapour pressure, and first studies have been performed within the last years $[148,161,162,173,193-200]$. Compared to classical spectroscopy techniques used to monitor chemical reactions, the advantage of XPS is that through the analysis of their core levels all relevant elements can be quantified and their chemical state can be analysed under well-defined (ultraclean) conditions.

One of the first examples of following chemical reactions in situ in ILs was an organic liquid phase reaction, namely the alkylation of an amine under solvent-free conditions [197]. This was achieved by tethering the reactive groups to the cation of an ionic liquid $A$ and the anion of a different ionic liquid $B$. A macroscopically thick film of an equimolar mixture of these two ILs was then heated to $100{ }^{\circ} \mathrm{C}$ and the progress of the reaction over time was monitored by measuring the intensity of the relevant core levels of the reactants by XPS. From the quantitative analysis, it was possible to identify the targeted reaction and also undesired side reactions, along with their respective product yields.

Recently, this approach was taken one step further, by following a Brønsted acid-base reaction of a gaseous strong acid with the IL's anion acting as a base [198]. This study demonstrated the potential of XPS for studying reaction and diffusion phenomena at the gas/liquid interface; the applied model reaction represented a conceptionally simpler case than the first example, since it excludes the occurrence of side reactions. The investigated reaction between 1-methyl-3-octyl-imidazolium chloride $\left(\left[\mathrm{C}_{8} \mathrm{C}_{1} \mathrm{Im}\right] \mathrm{Cl}\right)$ and triflic acid $(\mathrm{TfOH})$ is schematically sketched in Fig. 8. In the course of this acid-base reaction reaction, a proton is transferred from $\mathrm{TfOH}$ to the chloride ion of the IL; thereby $\mathrm{HCl}$ and a $\left[\mathrm{TfO}^{-}{ }^{-}\right.$(triflate) anion are formed [198].

To follow the reaction, the surface of a $\sim 100 \mu \mathrm{m}$ thick $\left[\mathrm{C}_{8} \mathrm{C}_{1} \mathrm{Im}\right] \mathrm{Cl}$ film was exposed to gaseous $\mathrm{TfOH}$ at a partial pressure of $1 \times 10^{-6}$ mbar at room temperature; TfOH was provided through a leak valve connected to a reservoir with the liquid acid [198]. In Fig. 9, the F 1s, O 1s, S 2p, N $1 \mathrm{~s}, \mathrm{C} 1 \mathrm{~s}$ and $\mathrm{Cl} 2 \mathrm{p}$ core level regions are depicted for 


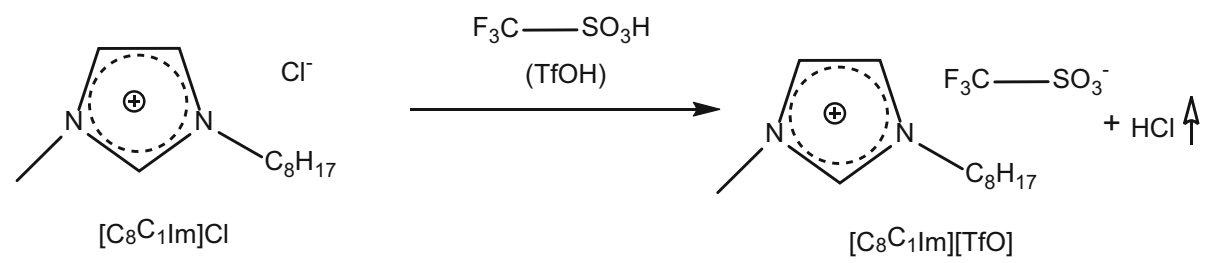

Fig. 8 Reaction of $\left[\mathrm{C}_{8} \mathrm{C}_{1} \mathrm{Im}\right] \mathrm{Cl}$ with volatile triflic acid TfOH to form a new $\mathrm{IL},\left[\mathrm{C}_{8} \mathrm{C}_{1} \mathrm{Im}\right][\mathrm{TfO}]$ and $\mathrm{HCl}$ that evaporates under UHV conditions. Reprinted with permission from Ref. [198]. Copyright 2013, Wiley

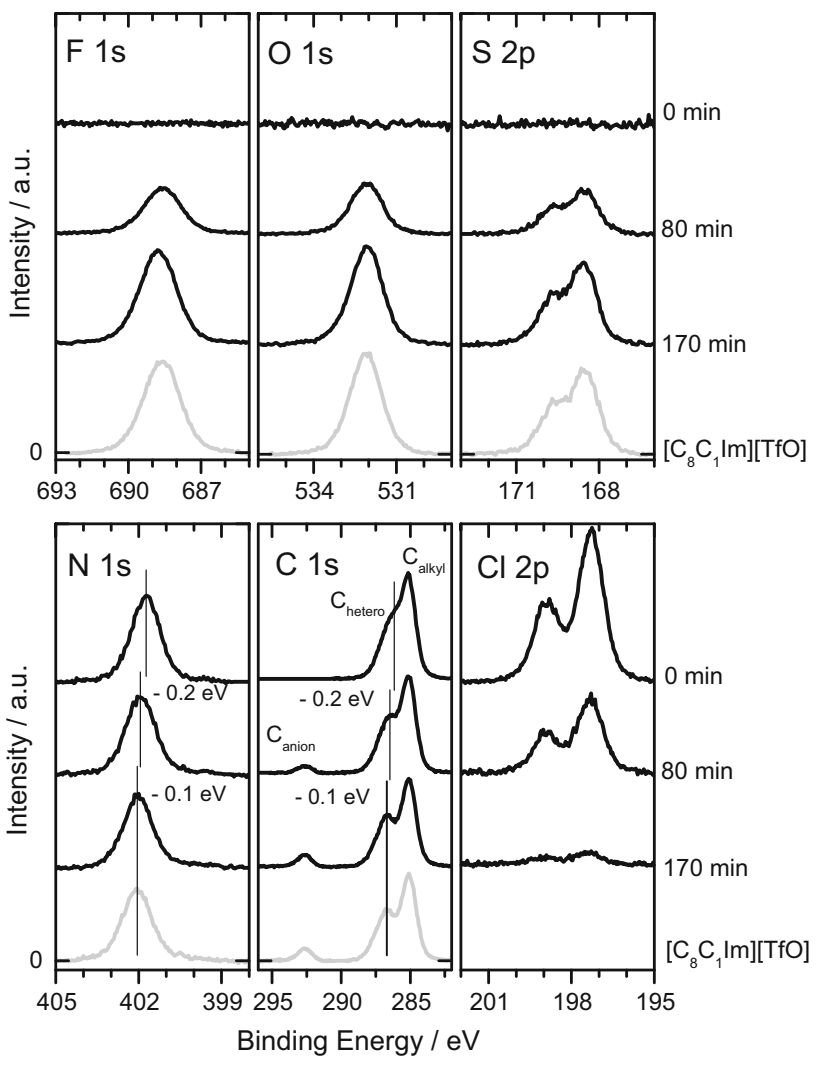

Fig. 9 Core level spectra of different regions before ( $0 \mathrm{~min})$, after $80 \mathrm{~min}$ and after $170 \mathrm{~min}$ total $\mathrm{TfOH}$ dosage time $\left(\mathrm{p}_{\mathrm{TfOH}}=\right.$ $1 \times 10^{-6}$ mbar). At the bottom of each series the spectra of pure $\left[\mathrm{C}_{8} \mathrm{C}_{1} \mathrm{Im}\right][\mathrm{TfO}]$ (grey) are shown for comparison. Gas dosage and XPS recording were performed at room temperature under normal emission conditions (information depth $\sim 7-9 \mathrm{~nm}$ ). Reprinted with permission from Ref. [198]. Copyright 2013, Wiley

different exposures to $\mathrm{TfOH}$. Prior to the reaction $(0 \mathrm{~min}$ exposure), the $\mathrm{N} 1 \mathrm{~s}, \mathrm{C} 1 \mathrm{~s}$ and $\mathrm{Cl} 2 \mathrm{p}$ signals of $\left[\mathrm{C}_{8} \mathrm{C}_{1} \mathrm{Im}\right] \mathrm{Cl}$ were observed with the expected intensities, and no signals were found in the other regions studied. After exposure to $\mathrm{TfOH}$, new signals emerged in the $\mathrm{F} 1 \mathrm{~s}, \mathrm{O} 1 \mathrm{~s}, \mathrm{C} 1 \mathrm{~s}$ and S 2p regions, at binding energies of 688.5, 532.0, 292.6 and $169.7 \mathrm{eV}$, respectively. These are assigned to the newly formed [TfO] $]^{-}$anion. Simultaneously, the $\mathrm{Cl} 2 \mathrm{p}$ signals of the chloride ion decreased in intensity. The initial $\mathrm{Cl} 2 \mathrm{p}$ intensity dropped down to $\sim 50 \%$ after 80 min dosage, and to $\sim 9 \%$ after $170 \mathrm{~min}$. At the same time, the $[\mathrm{TfO}]^{-}$ signals increased accordingly. This indicates that (within the information depth of XPS) the $\mathrm{Cl}^{-}$anions $\left[\mathrm{C}_{8} \mathrm{C}_{1} \mathrm{Im}\right] \mathrm{Cl}$ have nearly completely reacted with $\mathrm{TfOH}$ to $\left[\mathrm{C}_{8} \mathrm{C}_{1}\right.$. $\mathrm{Im}][\mathrm{TfO}]$ and volatile $\mathrm{HCl}$. As no $\mathrm{Cl} 2 \mathrm{p}$ peaks due other $\mathrm{Cl}$ species, that is, covalently bound $\mathrm{Cl}$ or $\mathrm{Cl}_{2}$, are observed, the proton transfer/anion exchange was identified as the only process taking place under the applied conditions. This is further confirmed by comparison to the spectrum of a pure $\left[\mathrm{C}_{8} \mathrm{C}_{1} \mathrm{Im}\right][\mathrm{TfO}]$ layer (grey spectra in Fig. 9).

Additional insight can be obtained from the detailed analysis of the $\mathrm{C} 1 \mathrm{~s}$ and $\mathrm{N} 1 \mathrm{~s}$ core levels. The $\mathrm{C} 1 \mathrm{~s}$ peaks at $285.0 \mathrm{eV}\left(\mathrm{C}_{\text {alkyl }}\right)$ and $\sim 286 \mathrm{eV}\left(\mathrm{C}_{\text {hetero }}\right)$ as well as the $\mathrm{N}$ 1s signals solely originate from the IL cation, which is not involved in the acid-base reaction. Their decrease by $12-14 \%$ in the course of the reaction directly reflects the overall change of the IL density, due to the exchange of the small $\mathrm{Cl}^{-}$anion by the considerably larger $[\mathrm{TfO}]^{-}$anion.

The presented results demonstrated nearly complete conversion from $\left[\mathrm{C}_{8} \mathrm{C}_{1} \mathrm{Im}\right] \mathrm{Cl}$ to $\left[\mathrm{C}_{8} \mathrm{C}_{1} \mathrm{Im}\right][\mathrm{TfO}]$, at least within the information depth of XPS (7-9 nm). It is important to note, however, that due to mass transfer limitations complete conversion was restricted to the near surface region of the macroscopic IL film. While storage of the reacted IL under UHV for $30 \mathrm{~h}$ did not change the XP spectra, upon heating to $370 \mathrm{~K}$ for $1 \mathrm{~h}$ (to decrease viscosity and increase ion mobility) distinct changes occurred: The [TfO $^{-}$peaks decreased to $47 \pm 8 \%$ of their maximum intensities and, simultaneously, the $\mathrm{Cl} 2 \mathrm{p}$ doublet reappeared. This recovery effect resulted from diffusion of $\mathrm{Cl}^{-}$anions from the IL bulk region, where no reaction occurred under the applied conditions, to the near-surface region [198].

\section{Conclusions}

The aim of this review was to relate general aspects in ILbased catalysis to molecular aspects as studied by modern surface science techniques. For this purpose we first presented the most important classes of IL-based catalytic reactions, namely acid-catalyzed and transition metal-catalyzed reactions in both liquid-ionic liquid biphasic and 
solid supported versions. The advantages and disadvantages of these technologies have been highlighted with a specific focus on practical aspects and technical application potential. From these considerations it is obvious that catalysis using thin IL films is particularly attractive as the IL utilization is very efficient and many practical problems of implementing new liquid materials into an industrial environment can be circumvented.

However, leveraging the full potential of IL thin film technologies requires a much better understanding of the IL interaction with solid surfaces and of the IL interface with liquids or gases. Due to the very low vapor pressure of ILs these scientific questions can be addressed using classical surface science methodologies, such as XPS. From these studies of the last ten years a much more detailed picture of the IL surface (as a function of IL structure), of segregation phenomena and of specific IL-surface as well as IL-catalyst interactions could be gained. This molecular insight proved already highly useful for interpreting experimental results. In the future these results may help to derive design principles and to advise optimization strategies, in particular for SILP and SCILL catalyst materials. Finally, it is correct to state that ionic liquid surface science in very general has greatly improved our knowledge about liquid surfaces and interfaces. Thus, the specific nature of ionic liquids does not only give access to new modes of catalysis but also to new and fundamental insights concerning the nature of liquids.

Acknowledgments H.-P.S. thanks his present and former coworkers Dr. Florian Maier, Dr. Till Cremer, Dr. Claudia Kolbeck, Inga Niedermaier, Florian Rietzler, Dr. Kevin Lovelock, Dr. Alexey Deyko, Dr. Takashi Matsuda for their great input and enduring enthusiasm in an outstanding cooperation. P.W. thanks all his coworkers who have contributed over the recent fifteen years to the development of catalysis concepts with ionic liquids, in particular the senior scientists Dr. Peter Schulz, Dr. Marco Haumann and Dr. Nicola Taccardi. Financial support through the Cluster of Excellence "Engineering of Advanced Materials", SPP 1191 "Ionic Liquids" and grant STE 620/9-1 is gratefully acknowledged.

\section{References}

1. For detailed reading see the final report of the DFG priority programme "Ionic Liquids" (SPP 1191) published as Wasserscheid P, Schroer W (eds) (2014) J Mol Liq 192:1-208

2. Wasserscheid P, Welton T (2007) Ionic liquids in synthesis, monograph in two volumes. Wiley, Weinheim

3. Smiglak M, Pringle JM, Lu X, Han L, Zhang S, Gao H, MacFarlane DR, Rogers RD (2014) Chem Commun 50:9228-9250

4. Fedorov MV, Kornyshev AA (2014) Chem Soc Rev 114:2978-3036

5. Estager J, Holbrey JD, Swadźba-Kwaśny M (2014) Chem Soc Rev 43:847-886

6. Werner S, Haumann M, Wasserscheid P (2010) Ann Rev Chem Biomol Eng 1:203-230
7. NIST Ionic Liquids Database-(ILThermo); NIST Standard Reference Database \#147: http://ilthermo.boulder.nist.gov/ ILThermo/

8. Karodia N, Guise S, Newlands C, Andersen J-A (1998) Chem Commun 21:2341-2342

9. Wasserscheid P, van Hal R, Bösmann A (2002) Green Chem 4:400-404

10. Wasserscheid P, Sesing M, Korth W (2002) Green Chem 4:134-138

11. Visser AE, Swatloski RP, Reichert WM, Mayton R, Sheff S, Wierzbicki A, Davis JH Jr, Rogers RD (2001) Chem Commun 1:135-136

12. Merrigan TL, Bates ED, Dorman SC, Davis JH Jr (2000) Chem Commun 20:2051-2052

13. Hardacre C, Holbrey JD, McMath SEJ (2001) Chem Commun $4: 367-368$

14. Wasserscheid P, Bösmann A, Bolm C (2002) Chem Commun 2:200-201

15. Kakiuchi T (2008) Anal Sci 24:1221-1230

16. Kolbeck C, Lehmann J, Lovelock KRJ, Cremer T, Paape N, Wasserscheid P, Fröba AP, Maier F, Steinrück H-P (2010) J Phys Chem B 114(51):17025-17036

17. Koller T, Rausch MH, Schulz PS, Berger M, Wasserscheid P, Economou IG, Leipertz A, Fröba AP (2012) J Chem Eng Data 57(3):828-835

18. Koller TM, Rausch MH, Ramos J, Schulz PS, Wasserscheid P, Economou IG, Fröba AP (2013) J Phys Chem B 117(28):8512-8523

19. Lei Z, Arlt W, Wasserscheid P (2006) Fluid Phase Equilib 241:290-299

20. Jork C, Kristen C, Pieraccini D, Stark A, Chiappe C, Beste YA, Arlt W (2005) J Chem Thermodyn 37:537-558

21. Earle M (2007) In: Wasserscheid P, Welton T (eds) Ionic liquids in synthesis. Wiley, Weinheim, pp 292-367

22. Camper D, Becker C, Koval C, Noble R (2006) Ind Eng Chem Res 45:445-450

23. Wang Y, Gong X, Wang Z, Dai L (2010) J Mol Catal A Chem 322:7-16

24. Noel M, Trulove PC, Osteryoung RA (1991) Anal Chem 63(24):2892-2896

25. Smith GP, Dworkin AS, Pagni RM, Zingg SP (1989) J Am Chem Soc 111:5075-5077

26. Boon JA, Levisky JA, Pflug JL, Wilkes JS (1986) J Org Chem 51(4):480-483

27. Abdul-Sada AAK, Atkins MP, Ellis B, Hodgson PKG, Morgan MLM, Seddon KR (1995) WO9521806A1

28. Sherif FG, Shyu L-J, Greco CC, Talma AG, Lacroix CPM (1998) WO9803454A1

29. Joni J, Schmitt D, Schulz PS, Lotz TJ, Wasserscheid P (2008) J Catal 258:401-409

30. Liu ZC, Meng XH, Zhang R, Xu CM (2009) Pet Sci Technol 27:226-237

31. Earle MJ, Seddon KR, Adams CJ, Roberts G (1998) Chem Commun 19:2097-2098

32. Surette JKD, Green L, Singer RD (1996) Chem Commun 2753-2754

33. Brausch N, Metlen A, Wasserscheid P (2004) Chem Commun 10:1552-1553

34. Angueira EJ, White MG (2005) J Mol Catal A Chem 227:51-58

35. Zhao WJ, Jiang XZ (2006) Catal Lett 107:123-125

36. Stenzel O, Brüll R, Wahner UM, Sanderson RD, Raubenheimer HG (2003) J Mol Catal A: Chem 192:217-222

37. Adams CJ, Earle MJ, Seddon KR (2000) Green Chem 2:21-24

38. Xiao L, Johnson KE, Treble RB (2004) J Mol Catal A Chem 214:121-127 
39. Chauvin Y, Hirschauer A, Olivier H (1994) J Mol Catal 92(2):155-165

40. Yoo K, Namboodiri VV, Varma RS, Smirniotis PG (2004) J Catal 222(2):511-519

41. Aschauer S, Schilder L, Korth W, Fritschi S, Jess A (2011) Catal Lett 141(10): 1405-1419

42. Huang CP, Liu ZC, Xu CM, Chen BH, Liu YF (2004) Appl Catal A Gen 277(1-2):41-43

43. Liu Y, Hu R, Xu C, Su H (2008) Appl Catal A 346:189-193

44. Liu Z, Zhang RUI, Xu C, Xia R (2006) Oil Gas J 104(40):52-56

45. Xu C (2014) Presentation at the Gordon Research Conference „Green Chemistry “, 28/7/2014. New refinery alkylation process: composite using ionic liquid alkylation (CILA)

46. Hallett JP, Welton T (2011) Chem Rev 111(5):3508-3576

47. Keith AJ, Kosik SD, Tillekeratne LMV, Mason MR (2014) Synlett 25(7):977-982

48. Ambrose K, Hurisso BB, Singer RD (2013) Can J Chem 91(12):1258-1261

49. Autenrieth B, Willig F, Pursley D, Naumann S, Buchmeiser MR (2013) ChemCatChem 5(10):3033-3040

50. Wasserscheid P, Schulz PS (2007) In: Wasserscheid P, Welton T (eds) Ionic liquids in synthesis. Wiley, Weinheim, pp 558-569

51. Wu B, Liu W, Zhang Y, Wang H (2009) Chem Eur J $15: 1804-1810$

52. Geldbach T (2008) Organomet Chem 34:58-73

53. Parvulescu VI, Hardacre C (2007) Chem Rev 107:2615-2665

54. Haumann M, Riisager A (2008) Chem Rev 108:1474-1497

55. Olivier-Bourbigou H, Magna L, Morvan D (2010) Appl Catal A Gen 373(1-2): 1-56

56. Jutz F, Andanson JM, Baiker A (2011) Chem Rev 111(2):322-353

57. Scholten JD, Leal BC, Dupont J (2012) ACS Catal 2(1):184-200

58. Astruc D (2008) In: Dupont J, Silva DDO (eds) Nanoparticles and catalysis, transition-metal nanoparticle catalysis in imidazolium ionic liquids. Wiley, Weinheim, pp 195-218

59. Antonietti M, Kuang D, Smarsly B, Zhou Y (2004) Angew Chem Int Ed 43:4988-4992

60. Campbell PS, Prechtl MHG, Santini CC, Haumesser PH (2013) Curr Org Chem 17(4):414-429

61. Mehnert CP, Cook RA, Dispenziere NC, Afeworki M (2002) J Am Chem Soc 124:12932-12933

62. Mehnert CP (2005) Chem A Eur J 11(1):50-56

63. Riisager A, Wasserscheid P, van Hul R, Fehrmann R (2003) J Catal 219:452-455

64. Jakuttis M, Schönweiz A, Werner S, Franke R, Wiese K-D, Haumann M, Wasserscheid P (2011) Angew Chem Int Ed 50(19):4492-4495

65. Haumann M, Jakuttis M, Franke R, Schönweiz A, Wasserscheid P (2011) ChemCatChem 3:1822-1827

66. Mikkola J-P, Virtanen PP, Kordas K, Karhu H, Salmi TO (2007) Appl Catal A 328:68-76

67. Virtanen P, Karhu H, Kordas K, Mikkola J-P (2007) Chem Eng Sci 62:3660-3671

68. Öchsner E, Schneider MJ, Meyer C, Haumann M, Wasserscheid P (2011) Appl Catal A Gen 399(1-2):35-41

69. Hintermair U, Höfener T, Pullmann T, Francio G, Leitner W (2010) ChemCatChem 2:150-154

70. Werner S, Szesni N, Bittermann A, Schneider MJ, Härter P, Haumann M, Wasserscheid P (2010) Appl Catal A 377:70-75

71. Werner S, Szesni N, Kaiser M, Fischer RW, Haumann M, Wasserscheid P (2010) ChemCatChem 2:1399-1402

72. Duque R, Öchsner E, Clavier H, Caijo F, Nolan SP, Mauduit M, Cole-Hamilton DJ (2011) Green Chem 13:1187-1195

73. Scholz J, Loekman S, Szesni N, Hieringer W, Görling A, Haumann H, Wasserscheid P (2011) Adv Synth Catal 353:2701-2707
74. Breitenlechner S, Fleck M, Müller TE, Suppan A (2004) J Mol Catal A Chem 214:175-179

75. Riisager A, Jorgensen B, Wasserscheid P, Fehrmann R (2006) Chem Commun 9:994-996

76. Riisager A, Fehrmann R, Haumann H, Wasserscheid P (2006) Top Catal 40(1):91-102

77. Riisager A, Fehrmann R, Haumann H, Wasserscheid P (2006) Eur J Inorg Chem 4:695-706

78. Gu Y, Li G (2009) Adv Synth Catal 351(6):817-847

79. Van Doorslaer C, Wahlen J, Mertens P, Binnemans K, de Vos D (2010) Dalton Trans 39(36):8377-8390

80. Virtanen P, Salmi TO, Mikkola J-P (2010) Top Catal 53(15-18):1096-1103

81. Fehrmann R, Riisager A, Haumann M (2014) Supported ionic liquids. Wiley, Weinheim, pp 1-496

82. Haumann M, Schönweiz A, Breitzke H, Buntkowsky G, Werner S, Szesni N (2012) Chem Eng Technol 35(8):1421-1426

83. Lemus J, Palomar J, Gilarranz M, Rodriguez J (2011) Adsorption 17(3):561-571

84. Knapp R, Jentys A, Lercher JA (2009) Green Chem 11(5):656-661

85. Jess A, Kern C, Korth W (2012) OIL GAS European magazine, pp. $38-45$

86. Decastro C, Sauvage E, Valkenberg MH, Hölderich WF (2000) J Catal 196(1):86-94

87. Valkenberg MH, Hölderich WF (2002) Green Chem 4(88-93):2002

88. Joni J, Haumann H, Wasserscheid P (2009) Adv Synth Catal 351:423-431

89. Joni J, Haumann M, Wasserscheid P (2010) Appl Catal A 372(1):8-15

90. Kernchen U, Etzold BJM, Korth W, Jess A (2007) Chem Eng Technol 30(8):985-994

91. Arras JR, Paki E, Roth C, Radnik JR, Lucas M, Claus P (2010) J Phys Chem C 114(23):10520-10526

92. Steinrück H-P, Libuda J, Wasserscheid P, Cremer T, Kolbeck C, Laurin M, Maier F, Sobota M, Schulz PS, Stark M (2011) Adv Mater 23(22-23):2571-2587

93. Arras J, Steffan M, Shayeghi Y, Ruppert D, Claus P (2009) Green Chem 11(5):716-723

94. Jess A, Korth W, Etzold BJM (2007) DE102006019460A1

95. Arras J, Steffan M, Shayeghi Y, Claus P (2008) Chem Commun 4058-4060

96. Dyson PJ, Laurenczy G, Ohlin CA, Vallance J, Welton T (2003) Chem Commun 2418-2419

97. Wörz N, Arras J, Claus P (2011) Appl Catal A 391(1-2):319-324

98. Hagiwara H, Sasaki H, Tsubokawa N, Hoshi T, Suzuki T, Tsuda T, Kuwabata S (2010) Synlett 1990-1996

99. Endres F, El Abedin SZ (2006) Phys Chem Chem Phys $8: 2101-2116$

100. Baldelli S (2008) Acc Chem Res 41:421-431

101. Lynden-Bell RM, Del Popolo M (2006) Phys Chem Chem Phys 8:949-954

102. Steinrück H-P (2010) Surf Sci 604:481-484

103. Tariq M, Freire MG, Saramago B, Coutinho JAP, Lopes JNC, Rebelo LPN (2012) Chem Soc Rev 41:829-868

104. Endres F (2012) Phys Chem Chem Phys 14:5008-5009

105. Chiappe C, Pomelli CS, Bardi U, Caporali S (2012) Phys Chem Chem Phys 14:5045-5051

106. Lovelock KRJ (2012) Phys Chem Chem Phys 14:5071-5089

107. Steinrück H-P (2012) Phys Chem Chem Phys 14:5010-5029

108. Lovelock KRJ, Villar-Garcia IJ, Maier F, Steinrück H-P, Licence P (2010) Chem Rev 110:5158-5190

109. Santos CS, Baldelli S (2010) Chem Soc Rev 39:2136-2145

110. Aliaga C, Baldelli S (2006) J Phys Chem B 110:18481-18491 
111. Iimori T, Iwahashi T, Kanai K, Seki K, Sung JH, Kim D, Hamaguchi HO, Ouchi Y (2007) J Phys Chem B 111:4860-4866

112. Jeon Y, Sung J, Bu W, Vaknin D, Ouchi Y, Kim D (2008) J Phys Chem C 112:19649-19654

113. Penalber CY, Grenoble Z, Baker GA, Baldelli S (2012) Phys Chem Chem Phys 14:5122-5131

114. Baldelli S (2013) J Phys Chem Lett 4:244-252

115. Baldelli S, Bao JM, Wu W, Pei SS (2011) Chem Phys Lett 516:171-173

116. Penalber CY, Baker GA, Baldelli S (2013) J Phys Chem B 117:5939-5949

117. Bowers J, Vergara-Gutierrez MC, Webster JRP (2004) Langmuir 20:309-312

118. Solutskin E, Ocko BM, Taman L, Kuzmenko I, Gog T, Deutsch M (2005) J Am Chem Soc 127:7796-7804

119. Nishi N, Uruga $T$, Tanida H, Kakiuchi $T$ (2011) Langmuir 27:7531-7536

120. Nishi N, Yasui Y, Uruga T, Tanida H, Yamada T, Nakayama S, Matsuoka H, Kakiuchi T (2010) J Chem Phys 132:164705

121. Mezger M, Ocko BM, Reichert H, Deutsch M (2013) Proc Natl Acad Sci USA 110:3733-3737

122. Yano YF, Yamada H (2008) Anal Sci 24:1269-1271

123. Yokota Y, Hara H, Harada T, Imanishi A, Uemura T, Takeya J, Fukui KI (2013) Chem Commun 49:10596-10598

124. Yokota Y, Hara H, Morino Y, Bando K, Imanishi A, Uemura T, Takeya J, Fukui K (2014) Appl Phys Lett 104:263102

125. Yokota Y, Harada T, Fukui KI (2010) Chem Commun 46:8627-8629

126. Asencio RA, Cranston ED, Atkin R, Rutland MW (2012) Langmuir 28:9967-9976

127. Atkin R, Borisenko N, Druschler M, Endres F, Hayes R, Huber B, Roling B (2014) J Mol Liq 192:44-54

128. Endres F, Borisenko N, El Abedin SZ, Hayes R, Atkin R (2012) Faraday Discuss 154:221-233

129. Hayes R, Borisenko N, Tam MK, Howlett PC, Endres F, Atkin R (2011) J Phys Chem C 115:6855-6863

130. Hayes R, Warr GG, Atkin R (2010) Phys Chem Chem Phys 12:1709-1723

131. Li H, Endres F, Atkin R (2013) Phys Chem Chem Phys 15:14624-14633

132. Li H, Wood RJ, Endres F, Atkin R (2014) J Phys Condens Matter 26

133. Page AJ, Elbourne A, Stefanovic R, Addicoat MA, Warr GG, Voitchovsky K, Atkin R (2014) Nanoscale 6:8100-8106

134. Sweeney J, Webber GB, Rutland MW, Atkin R (2014) Phys Chem Chem Phys 16:16651-16658

135. Smith AM, Lovelock KRJ, Gosvami NN, Welton T, Perkin S (2013) Phys Chem Chem Phys 15:15317-15320

136. Smith AM, Lovelock KRJ, Perkin S (2013) Faraday Discuss 167:279-292

137. Perkin S (2012) Phys Chem Chem Phys 14:5052-5062

138. Krischok S, Eremtchenko M, Himmerlich M, Lorenz P, Uhlig J, Neumann A, Ottking R, Beenken WJD, Höfft O, Bahr S, Kempter V, Schaefer JA (2007) J Phys Chem B 111:4801-4806

139. Ulbrich A, Reinmöller M, Beenken WJD, Krischok S (2012) ChemPhysChem 13:1718-1724

140. Smith EF, Rutten FJM, Villar-Garcia IJ, Briggs D, Licence P (2006) Langmuir 22:9386-9392

141. Caporali S, Bardi U, Lavacchi A (2006) J Electron Spectrosc 151:4-8

142. Gottfried JM, Maier F, Rossa J, Gerhard D, Schulz PS, Wasserscheid P, Steinrück HP (2006) Z Phys Chem 220:1439-1453

143. Maier F, Cremer T, Kolbeck C, Lovelock KRJ, Paape N, Schulz PS, Wasserscheid P, Steinrück H-P (2010) Phys Chem Chem Phys 12:1905-1915
144. Silvester DS, Broder TL, Aldous L, Hardacre C, Crossley A, Compton RG (2007) Analyst 132:196-198

145. Lockett V, Sedev R, Bassell C, Ralston J (2008) Phys Chem Chem Phys 10:1330-1335

146. Kolbeck C, Cremer T, Lovelock KRJ, Paape N, Schulz PS, Wasserscheid P, Maier F, Steinrück H-P (2009) J Phys Chem B 113:8682-8688

147. Kolbeck C, Killian M, Maier F, Paape N, Wasserscheid P, Steinrück HP (2008) Langmuir 24:9500-9507

148. Niedermaier I, Kolbeck C, Taccardi N, Schulz PS, Li J, Drewello T, Wasserscheid P, Steinrück H-P, Maier F (2012) ChemPhysChem 13:1725-1735

149. Paape N, Wei W, Bösman A, Kolbeck C, Maier F, Steinrück HP, Wasserscheid P, Schulz PS (2008) Chem Commun 3867-3869

150. Cremer T, Killian M, Gottfried JM, Paape N, Wasserscheid P, Maier F, Steinrück HP (2008) ChemPhysChem 9:2185-2190

151. Cremer T, Kolbeck C, Lovelock KRJ, Paape N, Wölfel R, Schulz PS, Wasserscheid P, Weber H, Thar J, Kirchner B, Maier F, Steinrück H-P (2010) Chem Eur J 16:9018-9033

152. Lovelock KRJ, Kolbeck C, Cremer T, Paape N, Schulz PS, Wasserscheid P, Maier F, Steinrück HP (2009) J Phys Chem B 113:2854-2864

153. Fortunato R, Afonso CAM, Benavente J, Rodriguez-Castellon E, Crespo JG (2005) J Membr Sci 256:216-223

154. Taccardi N, Niedermaier I, Maier F, Steinrück H-P, Wasserscheid P (2012) Chem Eur J 18:8288-8291

155. Kolbeck C, Paape N, Cremer T, Schulz PS, Maier F, Steinrück H-P, Wasserscheid P (2010) Chem Eur J 16:12083-12087

156. Cremer T, Wibmer L, Calderon SK, Deyko A, Maier F, Steinrück H-P (2012) Phys Chem Chem Phys 14:5153-5163

157. Men S, Hurisso BB, Lovelock KRJ, Licence P (2012) Phys Chem Chem Phys 14:5229-5238

158. Ulbrich A, Reinmöller M, Beenken WJD, Krischok S (2014) J Mol Liq 192:77-86

159. Kolbeck C, Deyko A, Matsuda T, Kohler FTU, Wasserscheid P, Maier F, Steinrück H-P (2013) ChemPhysChem 14:3726-3730

160. Kolbeck C, Niedermaier I, Deyko A, Lovelock KRJ, Taccardi N, Wei W, Wasserscheid P, Maier F, Steinrück H-P (2014) Chem Eur J 20:3954-3965

161. Kolbeck C, Taccardi N, Paape N, Schulz PS, Wasserscheid P, Steinrück H-P, Maier F (2014) J Mol Liq 192:103-113

162. Niedermaier I, Bahlmann M, Papp C, Kolbeck C, Wei W, Calderon SK, Grabau M, Schulz PS, Wasserscheid P, Steinrück H-P, Maier F (2014) J Am Chem Soc 136:436-441

163. Deyko A, Cremer T, Rietzler F, Perkin S, Crowhurst L, Welton T, Steinrück H-P, Maier F (2013) J Phys Chem C 117:5101-5111

164. Rietzler F, Piermaier M, Deyko A, Steinrück H-P, Maier F (2014) Langmuir 30:1063-1071

165. Nishi T, Iwahashi T, Yamane H, Ouchi Y, Kanai K, Seki K (2008) Chem Phys Lett 455:213-217

166. Kanai K, Nishi T, Iwahashi T, Ouchi Y, Seki K, Harada Y, Shin S (2009) J Electron Spectrosc 174:110-115

167. Nakajima K, Ohno A, Suzuki M, Kimura K (2008) Langmuir $24: 4482-4484$

168. Hashimoto H, Ohno A, Nakajima K, Suzuki M, Tsuji H, Kimura K (2010) Surf Sci 604:464-469

169. Nakajima K, Miyashita M, Suzuki M, Kimura K (2013) J Chem Phys 139:224701

170. Nakajima K, Ohno A, Suzuki M, Kimura K (2009) Nucl Instrum Methods Phys Res Sect B 267:605-609

171. Nakajima K, Oshima S, Suzuki M, Kimura K (2012) Surf Sci 606:1693-1699

172. Sobota M, Nikiforidis I, Hieringer W, Paape N, Happel M, Steinrück H-P, Görling A, Wasserscheid P, Laurin M, Libuda J (2010) Langmuir 26:7199-7207 
173. Schernich S, Kostyshyn D, Wagner V, Taccardi N, Laurin M, Wasserscheid P, Libuda J (2014) J Phys Chem C 118:3188-3193

174. Schernich S, Wagner V, Taccardi N, Wasserscheid P, Laurin M, Libuda J (2014) Langmuir 30:6846-6851

175. Steinrück H-P, Libuda J, Wasserscheid P, Cremer T, Kolbeck C, Laurin M, Maier F, Sobota M, Schulz PS, Stark M (2011) Adv Mater 23:2571-2587

176. Law G, Watson PR, Carmichael AJ, Seddon KR, Seddon B (2001) Phys Chem Chem Phys 3:2879-2885

177. Waldmann T, Huang HH, Hoster HE, Höfft O, Endres F, Behm RJ (2011) ChemPhysChem 12:2565-2567

178. Borisenko N, El Abedin SZ, Endres F (2012) ChemPhysChem 13:1736-1742

179. Buchner F, Forster-Tonigold K, Uhl B, Alwast D, Wagner N, Farkhondeh H, Gross A, Behm RJ (2013) ACS Nano 7:7773-7784

180. Uhl B, Buchner F, Alwast D, Wagner N, Behm RJ (2013) Beilstein J Nanotechnol 4:903-918

181. Uhl B, Buchner F, Gabler S, Bozorgchenani M, Behm RJ (2014) Chem Commun 50:8601-8604

182. Hantal G, Voroshylova I, Cordeiro MNDS, Jorge M (2012) Phys Chem Chem Phys 14:5200-5213

183. Lisal M, Posel Z, Izak P (2012) Phys Chem Chem Phys 14:5164-5177

184. Lynden-Bell RM, Del Popolo MG, Youngs TGA, Kohanoff J, Hanke CG, Harper JB, Pinilla CC (2007) Acc Chem Res 40:1138-1145

185. Pinilla C, Del Popolo MG, Lynden-Bell RM, Kohanoff J (2005) J Phys Chem B 109:17922-17927

186. Jiang W, Wang YT, Yan TY, Voth GA (2008) J Phys Chem C 112:1132-1139

187. Jiang W, Yan TY, Wang YT, Voth GA (2008) J Phys Chem B 112:3121-3131

188. Chang TM, Dang LX (2009) J Phys Chem A 113:2127-2135

189. Sieffert N, Wipff G (2008) J Phys Chem C 112:6450-6461

190. Sieffert N, Wipff G (2008) J Phys Chem C 112:19590-19603

191. Lockett V, Sedev R, Harmer S, Ralston J, Horne M, Rodopoulos T (2010) Phys Chem Chem Phys 12:13816-13827

192. Cremer T, Stark M, Deyko A, Steinrüick H-P, Maier F (2011) Langmuir 27:3662-3671

193. Taylor AW, Qiu FL, Villar-Garcia IJ, Licence P (2009) Chem Commun 5817-5819

194. Lovelock KRJ, Smith EF, Deyko A, Villar-Garcia IJ, Licence P, Jones RG (2007) Chem Commun 4866-4868

195. Compton RG, Wibowo R, Aldous L, Jacobs RMJ, Manan NSA (2011) Chem Phys Lett 509:72-76

196. Kötz R, Weingarth D, Foelske-Schmitz A, Wokaun A (2011) Electrochem Commun 13:619-622
197. Kolbeck C, Niedermaier I, Taccardi N, Schulz PS, Maier F, Wasserscheid P, Steinrück HP (2012) Angew Chem Int Ed 51:2610-2613

198. Niedermaier I, Taccardi N, Wasserscheid P, Maier F, Steinrück H-P (2013) Angew Chem Int Ed 52:8904-8907

199. Schernich S, Laurin M, Lykhach Y, Steinrück H-P, Tsud N, Skala T, Prince KC, Taccardi N, Matolin V, Wasserscheid P, Libuda J (2013) J Phys Chem Lett 4:30-35

200. Schernich S, Laurin M, Lykhach Y, Tsud N, Sobota M, Skala T, Prince KC, Taccardi N, Wagner V, Steinrück H-P, Matolin V, Wasserscheid P, Libuda J (2013) ChemPhysChem 14:3673-3677

201. Duwez AS (2004) J Electron Spectrosc 134:97-138

202. Kolbeck C, Lehmann J, Lovelock KRJ, Cremer T, Paape N, Wasserscheid P, Fröba AP, Maier F, Steinrück H-P (2010) J Phys Chem B 114:17025-17036

203. Maier F, Gottfried JM, Rossa J, Gerhard D, Schulz PS, Schwieger W, Wasserscheid P, Steinrück HP (2006) Angew Chem Int Ed 45:7778-7780

204. Sun P, Armstrong DW (2010) Anal Chim Acta 661:1-16

205. Hapiot P, Lagrost C (2008) Chem Rev 108:2238-2264

206. Dupont J, Scholten JD (2010) Chem Soc Rev 39:1780-1804

207. Payal RS, Balasubramanian S (2012) ChemPhysChem 13:1764-1771

208. Atkin R, Borisenko N, Druschler M, El Abedin SZ, Endres F, Hayes R, Huber B, Roling B (2011) Phys Chem Chem Phys 13:6849-6857

209. Mezger M, Schramm S, Schroder H, Reichert H, Deutsch M, De Souza EJ, Okasinski JS, Ocko BM, Honkimaki V, Dosch H (2009) J Chem Phys 131:094701

210. Kislenko SA, Samoylov IS, Amirov RH (2009) Phys Chem Chem Phys 11:5584-5590

211. Liu L, Li S, Cao Z, Peng YX, Li GR, Yan TY, Gao XP (2007) J Phys Chem C 111:12161-12164

212. Sha ML, Zhang FC, Wu GZ, Fang HP, Wang CL, Chen SM, Zhang Y, Hu J (2008) J Chem Phys 128:134504

213. Rollins JB, Fitchett BD, Conboy JC (2007) J Phys Chem B 111:4990-4999

214. Endres F, Höfft O, Borisenko N, Gasparotto LH, Prowald A, AlSalman R, Carstens T, Atkin R, Bund A, El Abedin SZ (2010) Phys Chem Chem Phys 12:1724-1732

215. Morino Y, Kanai Y, Imanishi A, Yokota Y, Fukui K (2014) Jpn J Appl Phys 53:05FY01

216. Armstrong JP, Hurst C, Jones RG, Licence P, Lovelock KRJ, Satterley CJ, Villar-Garcia IJ (2007) Phys Chem Chem Phys 9:982-990

217. Uhl B, Cremer T, Roos M, Maier F, Steinrück H-P, Behm J (2013) Phys Chem Chem Phys 15:17295-17302 